\title{
RFamide-Related Peptide Neurons Modulate Reproductive Function and Stress Responses
}

\author{
${ }^{(1)}$ Asha Mamgain, ${ }^{\circledR}$ India L. Sawyer, David A.M. Timajo, Mohammed Z. Rizwan, Maggie C. Evans, \\ Caroline M. Ancel, Megan A. Inglis, and ${ }^{\circledR}$ Greg M. Anderson \\ Centre for Neuroendocrinology and Department of Anatomy, University of Otago School of Biomedical Sciences, Dunedin 9054, New Zealand
}

RF-amide related peptide 3 (RFRP-3) is a neuropeptide thought to inhibit central regulation of fertility. We investigated whether alterations in RFRP neuronal activity led to changes in puberty onset, fertility, and stress responses, including stress and glucocorticoid-induced suppression of pulsatile luteinizing hormone secretion. We first validated a novel RFRP-Cre mouse line, which we then used in combination with Cre-dependent neuronal ablation and DREADD technology to selectively ablate, stimulate, and inhibit RFRP neurons to interrogate their physiological roles in the regulation of fertility and stress responses. Chronic RFRP neuronal activation delayed male puberty onset and female reproductive cycle progression, but RFRP-activated and ablated mice exhibited apparently normal fertility. When subjected to either restraint- or glucocorticoidinduced stress paradigms. However, we observed a critical sex-specific role for RFRP neurons in mediating acute and chronic stress-induced reproductive suppression. Female mice exhibiting RFRP neuron ablation or silencing did not exhibit the stress-induced suppression in pulsatile luteinizing hormone secretion observed in control mice. Furthermore, RFRP neuronal activation markedly stimulated glucocorticoid secretion, demonstrating a feedback loop whereby stressful stimuli activate RFRP neurons, which in turn further activate the stress axis. These data provide evidence for a neuronal link between the stress and reproductive axes.

Key words: fertility; HPA axis; puberty; reproduction; RFRP; stress

Significance Statement

The neuronal pathways whereby psychosocial stress leads to suppression of reproduction remain poorly understood; however, the neurons that drive the reproductive axis are thought to be indirectly influenced by stress steroids and neuropeptides in a sex-specific manner. We used in vivo testing in combination with Cre-dependent neuronal ablation and DREADD technology to demonstrate a physiological necessity of hypothalamic RF-amide related peptide (RFRP) neurons as mediators of stressinduced suppression of pulsatile reproductive hormone secretion. This effect was specific to females. We also reveal a causative link between RFRP neuronal function and the hormonal stress axis. Our findings suggest that pharmacological blockade of the receptors acted on by RFRP neuronal secretions could be used to overcome clinical infertility associated with stress or affective disorders.

\section{Introduction}

Reproductive function is regulated by the hypothalamo-pituitary-gonadal (HPG) hormonal axis. Hypothalamic gonadotropin-releasing hormone $(\mathrm{GnRH})$ neurons are the cumulative endpoint of inputs from a complex afferent neuronal system that integrates appropriate inhibitory and stimulatory signals to

\footnotetext{
Received May 4, 2020; revised 0ct. 30, 2020; accepted Nov. 15, 2020.

Author contributions: A.M., I.L.S., D.A.M.T., M.Z.R., C.M.A., M.A.I., and G.M.A. performed research; M.C.E. and G.M.A. analyzed data; M.C.E. wrote the first draft of the paper; M.C.E. wrote the paper; G.M.A. designed research; G.M.A. edited the paper.

This work was supported by the New Zealand Marsden Fund and the Health Research Council of New Zealand.

The authors declare no competing financial interests.

Correspondence should be addressed to Greg M. Anderson at greg.anderson@otago.ac.nz.

https://doi.org/10.1523/JNEUROSCl.1062-20.2020

Copyright $\odot 2021$ the authors
}

maintain optimal pituitary gonadotrophin (luteinizing hormone $[\mathrm{LH}]$ and follicle-stimulating hormone) secretion and reproductive function. Estrogens are the primary feedback signal to this neuronal network from the gonads, but other reproductive modulators also transmit key information centrally to regulate the HPG axis. For example, it is well established that both acute and chronic stress influence fertility, almost always negatively, in humans and animals (Ferin, 1999; Geraghty and Kaufer, 2015), although empirical clinical evidence for this is scarce. While acute stress responses may serve to delay reproduction until a more appropriate time, chronic stress exposure may lead to persistent infertility. Stress-induced reproductive dysfunction is often associated with increased activation of the hypothalamic-pituitaryadrenal (HPA) axis and sustained glucocorticoid release, yet the precise mechanism(s) whereby increased glucocorticoid 
levels suppress $\mathrm{GnRH} / \mathrm{LH}$ secretion remain to be fully elucidated.

GnRH neurons themselves do not appear to be major targets of either corticotropin-releasing hormone ( $\mathrm{CRH}$; the neuropeptide governing the HPA axis) or glucocorticoids, as only a small fraction of GnRH cells contain CRH (Jasoni et al., 2005) or glucocorticoid receptors (Dufourny and Skinner, 2002). RFamiderelated peptide-3 (RFRP-3) is a peptide secreted by RFRP neurons that project from the rodent dorsomedial hypothalamus (DMH), and is mostly (but not exclusively) inhibitory to $\mathrm{GnRH}$ activity (Ducret et al., 2009; Rizwan et al., 2009; Wu et al., 2009; Ancel et al., 2017). Interestingly, acute restraint stress was shown to suppress LH pulsatility while concomitantly increasing RFRP neuronal activation in male mice (Yang et al., 2018), and the activity of RFRP neurons was also upregulated by restraint stress in male rats (Kirby et al., 2009), suggesting that RFRP neurons may play a role in mediating the suppressive effects of stress on the HPG axis. Furthermore, approximately half of RFRP neurons express glucocorticoid receptors, and the effect of restraint stress on $R f r p$ gene expression was blocked by adrenalectomy (Kirby et al., 2009), suggesting that adrenal glucocorticoids activate RFRP neurons in stressful situations. Together with the established role of RFRP-3 in reproductive suppression, these findings position RFRP neurons as possible mediators of stress-induced suppression of the HPG axis, either by acting as conduits for glucocorticoid signals or by directly responding to stressful situations.

In the present study, we first validated and characterized a novel RFRP-Cre mouse line, which we then used to investigate the stress and reproductive effects of both stimulating and silencing RFRP neurons in vivo. We did this by generating male and female mice expressing RFRP-specific excitatory or inhibitory DREADDs (designer receptor exclusively activated by designer drugs) and also by ablating RFRP neurons using specifically targeted diphtheria toxin treatment. We then characterized different parameters of the stress and reproductive axes in response to acute and/or chronic RFRP neuronal activation to determine whether RFRP neurons play a key modulatory role on either axis. The effects of an acute restraint stress or chronic corticosterone exposure on LH pulsatility were examined in RFRP neuron-silenced or -ablated mice, while acute RFRP neuronal activation was used to test whether these neurons drive the HPA axis. The results highlight the importance of RFRP neurons for appropriate modulation of both the HPG and HPA axes functionality.

\section{Materials and Methods \\ Animals}

All mice were obtained from the University of Otago animal breeding facility. They were group housed in individually ventilated cages and maintained on a $12 \mathrm{~h}: 12 \mathrm{~h}$ light:dark cycle (lights on at $0600 \mathrm{~h}$ ) at a constant temperature $\left(21 \pm 1^{\circ} \mathrm{C}\right)$, with ad libitum access to food and water. All mouse lines used were of C57BL/6 background strain. For hormonal sampling experiments, all mice were habituated to the handling daily for at least 1 week before blood collection, and for LH sampling female mice were sampled on the day of diestrus of the reproductive cycle (determined by daily vaginal cytology). Samples were collected in the morning (first half of the light phase), except following acute oral clozapine-N-oxide $(\mathrm{CNO})$ administration, where the drug was fed at the beginning of the dark phase to encourage immediate consumption. The University of Otago Animal Ethics Committee approved all animal protocols.

\section{Generation of RFRP-Cre mouse}

Rfrp-IRES-Cre conditional knock-in mice were generated using homologous recombination in mouse embryonic stem cells (Beglopoulos and
Shen, 2004) by Ozgene, so that the knock-in allele produced a bicistronic Npvf (the gene encoding RFRP peptides) and Cre mRNA. The targeting vector consisted of $5^{\prime}$ and $3^{\prime}$ arms ( $\sim 4$ and $\sim 6 \mathrm{~kb}$ in length, respectively) of sequence homologous to the Npvf gene, an internal ribosomal entry sequence (IRES) linked to Cre recombinase and an FRT-flanked neomycin resistance gene. The IRES and Cre sequence was targeted into the $3^{\prime}$ untranslated region immediately downstream of the termination codon within the Npvf gene (NCBI database Gene ID: 60531; Ensembl gene report ID: ENSMUSG00000029831) (see Fig. 1A). Correct targeting of the IRES-Cre was confirmed by Southern blotting using $5^{\prime}$ - and $3^{\prime}$ probes located outside the targeting vector. DNA was extracted using lysis buffer containing proteinase K. Following extraction, genomic DNA was digested overnight with ScaI and run on an agarose gel, transferred to a nylon membrane by capillary transfer and screened by hybridization of a probe complementary to sequences located on the $5^{\prime}$ homology arm of the targeting construct. Probe hybridization produced an $18.8 \mathrm{~kb}$ band from the WT allele, while the correctly targeted allele generates a $9.0 \mathrm{~kb}$ band (see Fig. $1 B$ ). Completed constructs were electroporated into Bruce $4 \mathrm{C} 57 \mathrm{BL} / 6$ embryonic stem cells, and then chimeric mice were generated using blastocyst manipulation techniques. Chimeric mice were bred to C57BL/6 mice to identify germline transmission of the targeted gene, and then FLPe-deleter mice used to remove the FRT-flanked neomycin selection cassette. FLP-mediated excision of the selection cassette was verified by PCR analysis (see Fig. 1C).

\section{Validation of RFRP-Cre mouse}

To confirm Cre expression was targeted appropriately to RFRP cells, homozygous Rfrp-IRES-Cre mice were crossed with homozygous Credependent Tau-GFP (ROSA26-CAGS- $\tau$ GFP) (Mayer et al., 2010) reporter mice to generate mice exhibiting endogenous tau-GFP exclusively in Cre-expressing cells.

Endogenous tau-GFP-expressing cells were then compared with RFRP-3-expressing cells using immunohistochemistry. To this end, male and female RFRP-tau-GFP mice ( $n=6$ per group) were anesthetized with $250 \mathrm{mg} / \mathrm{kg}$ sodium pentobarbital and perfused through the heart with $4 \%$ PFA in $0.1 \mathrm{~m}$ PBS, pH 7.4. Brains were removed, postfixed in PFA, and cryoprotected in $30 \%$ sucrose solution. Coronal $(30-\mu \mathrm{m}-$ thick) sections from the DMH were cut from each brain on a sliding microtome with a freezing stage to provide three sets of consecutive sections $(90 \mu \mathrm{m}$ apart). One series of brain tissue from each animal was then used to dual-label for GFP- and RFRP-3-immunoreactive cells using fluorescent immunohistochemistry.

\section{Generation and validation of RFRP-hM3Dq knock-in mice}

We crossed RFRP-Cre mice with Cre-dependent hM3Dq DREADD mice (hM3Dq-DREADD mice, Jax strain 026220) to generate mice with RFRPdependent expression of the activating hM3Dq receptor. Following Cremediated removal of the poly A STOP cassette, expression of hM3Dq, a yellow fluorescent reporter protein (mCitrine) and hemagglutinin (HA), is observed. Binding of the hM3Dq receptor by the synthetic molecule CNO induces the canonical Gq pathway, leading to RFRP neuronal activity/neuronal firing. Offspring expressing both an RFRP-Cre and an hM3DqDREADD allele became the "knock-in" treatment (RFRP-hM3Dq) mice, whereas Cre-positive, hM3Dq-DREADD-negative (males, $n=8$; females, $n=6$ ) and Cre-negative, hM3Dq-DREADD-positive (males, $n=11$; females, $n=14$ ) mice were used as control animals.

To confirm RFRP neuron-specific expression of hM3Dq receptors in RFRP-hM3Dq mice, dual-label fluorescence immunohistochemistry for RFRP-3 and GFP (to label citrine) was performed in the DMH of male and female RFRP-hM3Dq and control mice. To confirm that CNO was able to activate RFRP neurons, cFos was colocalized with either RFRP-3 or HA using chromagenic dual-label immunohistochemistry in RFRP$\mathrm{hM} 3 \mathrm{Dq}$ and control mice perfused $1 \mathrm{~h}$ after treatment with CNO (1 mg/ $\mathrm{kg}$ s.c.).

Stimulation of glucocorticoid secretion by acute RFRP neuronal activation

Male RFRP-hM3Dq or control mice were acutely treated with CNO (either $1-2 \mathrm{mg} / \mathrm{kg}$ s.c. or $5 \mathrm{mg} / \mathrm{kg}$ p.o.) to investigate the effects of RFRP 
neuronal activation on corticosterone release, as central RFRP-3 injections have been shown to stimulate corticosterone release (Kim et al., 2015). The oral route was designed to eliminate handling stress, which can mask treatment effects on circulating glucocorticoid levels, even in habituated mice. For this, the mice were individually housed and trained to eat a bolus of hazelnut spread (Nutella) within $1 \mathrm{~min}$. On the day of the experiment, they were given $\mathrm{CNO}$ either p.o. in $20 \mathrm{mg}$ Nutella or subcutaneously in $0.2 \mathrm{ml}$ saline, and a single tail-tip blood sample $(\sim 25 \mu \mathrm{l})$ collected after $90 \mathrm{~min}$ using a heparinized capillary tube. Plasma was harvested and stored at $-20^{\circ} \mathrm{C}$ for corticosterone analysis.

Reproductive effects of chronic RFRP neuronal activation

To determine the effects of RFRP-3 neuronal activation on puberty onset, male and female RFRP-hM3Dq or control mice were chronically treated with $\mathrm{CNO}$ in their drinking water $(0.025 \mathrm{mg} / \mathrm{ml}$ p.o., which equates to $\sim 0.125 \mathrm{mg}$ CNO daily) from postnatal day (PND) 26-35. Age at vaginal opening and first estrus were used as markers of puberty onset in females, and puberty onset in males was determined as the age that preputial separation occurred.

To determine the impact of chronic RFRP-3 neuronal activation on the age that males became reproductively competent, male mice were again treated with $\mathrm{CNO}$ in their drinking water from PND 43-52 and paired with a reproductively experienced WT female and the age of the first successful mating was determined based on the date of the first litter, assuming a gestation of $20 \mathrm{~d}$.

To determine the impact of chronic RFRP-3 neuronal activation on estrous cyclicity, 7-week-old female mice were habituated to vaginal smearing for at least 1 week. After $7 \mathrm{~d}$ of daily vaginal smearing and cycle stage recording under normal conditions, all mice were treated with $\mathrm{CNO}$ in their drinking water $(0.025 \mathrm{mg} / \mathrm{ml} \mathrm{p.o.)} \mathrm{for} \mathrm{a} \mathrm{further} 7 \mathrm{~d}$, during which period daily vaginal smearing and cycle stage recording continued. Cycle length was calculated as the number of days between estrus occurrences (not counting any uninterrupted successive days). Where only one estrus occurrence was seen during the $\mathrm{CNO}$ administration period, an estrus from the day prior was used to enable calculation of cycle length. In one case where no estrus events occurred during $\mathrm{CNO}$ administration, a cycle length of $7 \mathrm{~d}$ was assigned for the purposes of data analysis.

Last, to determine the effect of RFRP-3 neuronal activation on female fertility, 10week-old mice were treated with $\mathrm{CNO}$ in their drinking water for $7 \mathrm{~d}$. On day 4 of CNO treatment, females were individually paired with sexually mature WT males. The time taken to successfully mate was determined using the date of birth of the first litter assuming a gestation of $20 \mathrm{~d}$. The number of pups per litter was also recorded.

\section{A Cre construct}
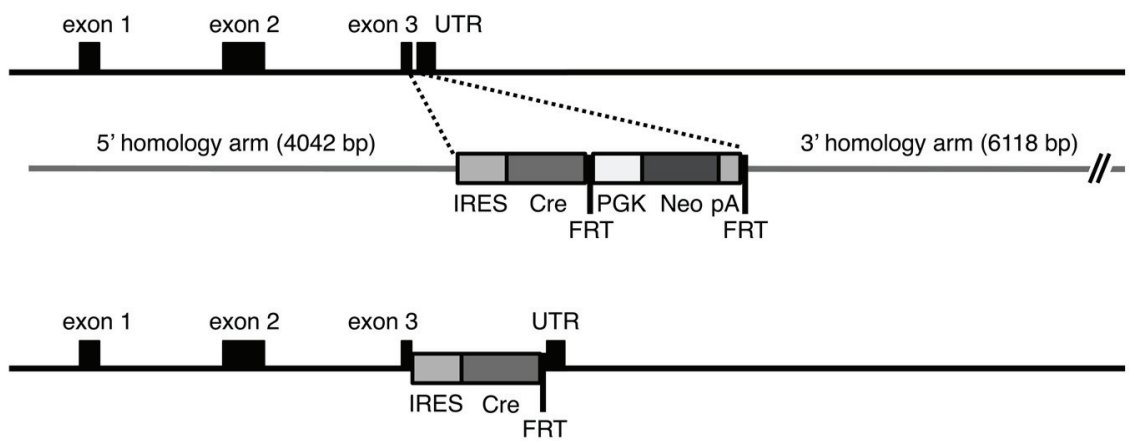

B

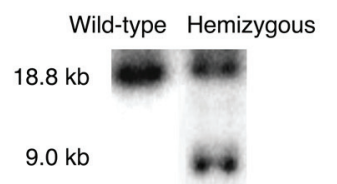

D RFRP-Cre-GFP coronal series (Bregma -1.0 - $2.5 \mathrm{~mm}$ )
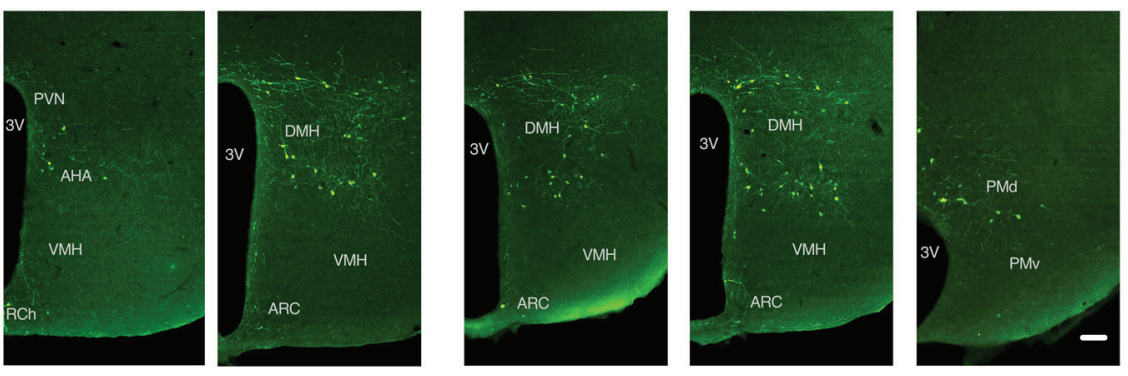

\section{E RFRP-3}

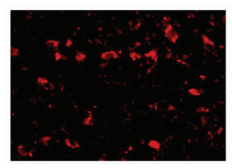

\section{F RFRP-Cre-GFP G Merge}
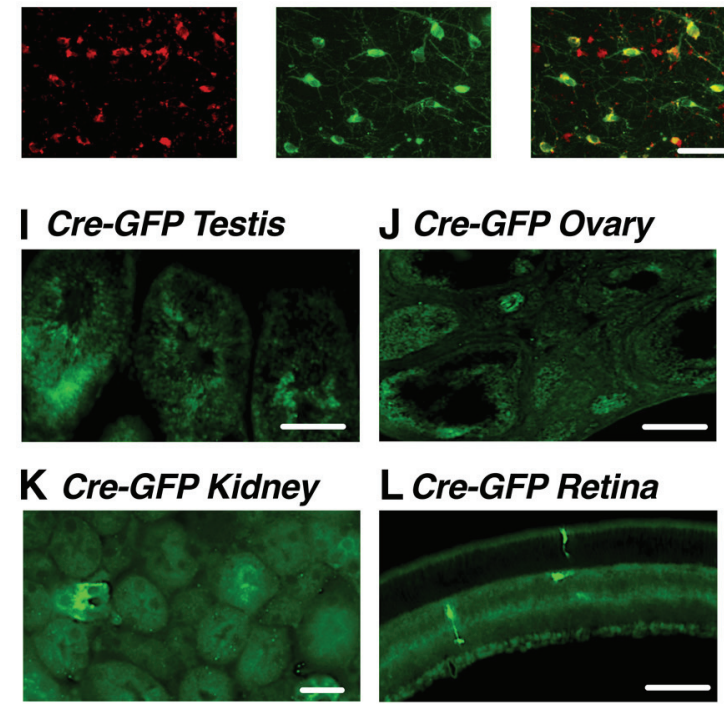

\section{Cre-GFP Retina}

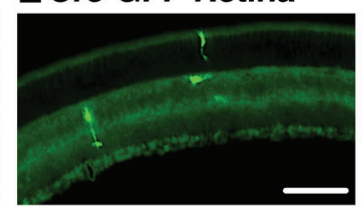

H Percent co-expression
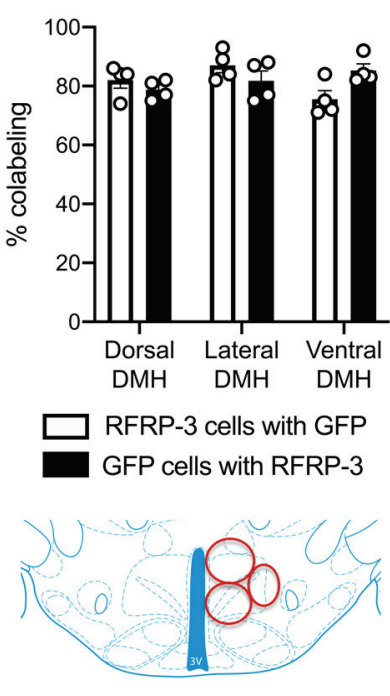

Figure 1. Generation and validation of a novel RFRP-Cre mouse line. $A$, Schematic diagram of the knock-in strategy used for generating RFRP-Cre mouse line. $\boldsymbol{B}$, Southern blot showing correct targeting of the mutant $(9.0 \mathrm{~kb})$ allele. $\boldsymbol{C}$, PCR gel confirming removal of the neomycin cassette (absence of $411 \mathrm{bp}$ band in Neo- lane). $\boldsymbol{D}$, Representative images from female mice showing RFRP-Cre-GFP expression throughout the DMH. $\boldsymbol{E}-\boldsymbol{G}$, Representative images from female mice showing RFRP-3 (D, red) and RFRP-Cre-GFP $(\boldsymbol{E}$, green) coexpression $(\boldsymbol{F}$, yellow) in the DMH. $\boldsymbol{H}$, Quantification of RFRP-Cre-GFP-immunolabeled neurons coexpressing RFRP-3 protein $(n=6$ per group) in the dorsal, lateral, and ventral DMH, respectively, which are depicted by the red circles in the schematic. Representative images showing nonbrain RFRP-Cre-GFP expression in $(\boldsymbol{I})$ testis, $(\boldsymbol{I})$ ovary, and a male $(\boldsymbol{K})$ kidney and $(\boldsymbol{L})$ retina. Data are mean \pm SEM. UTR, Untranslated region; PGK, phosphoglycerate kinase I promoter; Neo, neomycin resistance gene; pA, polyadenylation site; FRT, flippase recognition target; 3V, third ventricle; AHA, anterior hypothalamic area; RCH, retrochiasmatic nudleus; ARC, arcuate nucleus; VMH, ventral medial nucleus; PMv, ventral premammillary nucleus; PMd, dorsal premammillary nucleus. Scale bars, $50 \mu \mathrm{m}$. 
Generation and validation of RFRP-3 neuron-ablated mice

For experiments involving ablation of RFRP neurons, heterozygous Rfrp-IRES-Cre mice were crossed with mice homozygous for Cre-dependent diphtheria toxin receptor expression (Gt(ROSA)26Sor ${ }^{\mathrm{tm} 1}$ (HBEGF)Awai /J, The Jackson Laboratory, stock \#7900) (Buch et al., 2005). In these mice, the gene for simian diphtheria toxin receptor is ubiquitously present, but in normal circumstances is silenced by an upstream transcriptional blocker sequence that is flanked by two loxP sites. Cre recombinase in RFRP cells catalyzes loxP recombination, resulting in the excision of the stop sequence and diphtheria toxin receptor expression exclusively in RFRP neurons. Offspring that inherited a Rfrp-IRES-Cre allele were used as RFRP-ablated experimental animals, and littermates with WT RFRP alleles served as controls.

To induce RFRP neuronal ablation, adult mice at $\sim 8$ - 10 weeks of age received a single injection of diphtheria toxin $(0.05 \mathrm{mg} / \mathrm{kg}$ s.c. in $200 \mu \mathrm{l}$ saline) and allowed 4 weeks for sufficient neuronal ablation to take place. This dose was based on a pilot study in which $0.05,0.1$, or $1.5 \mathrm{mg} / \mathrm{kg}$ subcutaneous diphtheria toxin all caused pronounced ablation of RFRP neurons compared with Cre-negative controls 3 weeks after treatment $(0.04 \pm 0.04$ vs $12.8 \pm 1.1$ RFRP-3-immunoreactive neurons/brain section respectively; $p<0.01$ ). Because the highest dose caused some adverse health effects, we selected the $0.05 \mathrm{mg} / \mathrm{kg}$ dose for future experiments.

To confirm successful RFRP-3 neuronal ablation in diphtheria toxintreated RFRP-Cre-positive mice, chromagen immunohistochemistry for RFRP-3 was performed in 30- $\mu$ m-thick coronal brain tissue sections from diphtheria-treated Cre-positive and Cre-negative male and female mice ( $n=7-9$ mice per group) that were transcardially perfused with $4 \%$ PFA, as described previously (with nickel-enhanced DAB labeling). To confirm neuronal ablation was specific to RFRP-Cre-expressing cells, a second series of brain tissue sections from 5 mice per group was used for $\mathrm{TH}$ immunohistochemistry to visualize dopaminergic neurons in the zona inserta (A13 population), which neighbor the RFRP-3 neuronal populations.

Modulation of acute restraint stress effects on glucocorticoid and LH secretion by ablation of RFRP neurons

To assess HPA activation in response to an acute restrain stress, we measured circulating glucocorticoid concentrations in tail-tip blood samples that were collected in a heparinized capillary tube before and immediately after a 30 min restraint stress in a plastic restraint cone (Decapicome; Braintree Scientific) in both male and female RFRP-ablated and intact mice. Plasma concentrations of corticosterone were then measured using a commercial ELISA.

To determine whether RFRP neurons play a role in mediating the suppressive effects of acute restraint stress on LH pulsatility, RFRPablated and intact male and female mice were restrained for $30 \mathrm{~min}$ in a plastic restraint cone (Decapicone; Braintree Scientific), and LH pulsatility was assessed before, during, and after the restraint from tail tip blood samples $(4 \mu \mathrm{l}$ blood diluted in $50 \mu \mathrm{l}$ PBS and immediately frozen on dry ice) taken every $6 \mathrm{~min}$, starting $90 \mathrm{~min}$ before restraint (baseline, time 0 90 ), during the $30 \mathrm{~min}$ restraint period (time 90-120), and for an additional 45 min post-restraint (time 120-165). LH blood sampling was performed in the morning, and during diestrus in females.

\section{Reproductive characterization of RFRP-ablated mice}

To determine the impact of RFRP ablation on reproductive parameters, vaginal cytology was used to monitor estrous cyclicity in RFRP-ablated $(n=8)$ and control $(n=10)$ females, as described previously. Additionally, at the time of death, paired seminal vesicle weights were measured in males (control: $n=11$; RFRP-ablated: $n=13$ ) and uterine weights were measured in females (control: $n=10$; RFRP-ablated: $n=8$ ).

Generation and validation of RFRP-hM4Di knock-in mice

We crossed RFRP-Cre mice with Cre-dependent hM4Di DREADD mice (hM4Di-DREADD mice, Jax strain \#026219) to generate mice with RFRPdependent expression of the silencing hM4Di receptor. Following Cremediated removal of the poly A STOP cassette, expression of hM4Di is observed. Binding of the hM4Di receptor by $\mathrm{CNO}$ induces the canonical Gi pathway, leading to RFRP silencing of neuronal activity. Offspring expressing both an RFRP-Cre and an hM4Di-DREADD allele became the "knockin" treatment (RFRP-hM4Di) mice, while Cre-positive, hM4Di-DREADDnegative (males, $n=3$; females, $n=4$ ) and Cre-negative, hM4Di-DREADDpositive (males, $n=5$; females, $n=4$ ) mice were used as control animals.

To confirm that CNO was able to silence RFRP neurons, dual-label immunohistochemistry for fos-related antigens (FRAs, a marker of tonic neuronal activity) (Lehman et al., 1996; Szawka et al., 2010) and RFRP-3 was performed in brain sections from CNO-treated mice. All mice with chronic corticosterone implants were treated with $\mathrm{CNO}(2 \mathrm{mg} / \mathrm{kg}$ s.c.) 5 $\mathrm{h}$ before brain collection.

Modulation of glucocorticoid-induced suppression of pulsatile LH secretion by RFRP neuronal silencing

The previous experiment demonstrated the role for RFRP neurons in mediating acute stress-induced pulsatile LH suppression. Since stress often leads to elevated circulating glucocorticoid levels, and this elevation is able to disrupt LH pulses in female mice (Kreisman et al., 2020), we next sought to determine whether RFRP neurons could also mediate chronic glucocorticoid-induced LH pulse suppression. Furthermore, we tested whether acute silencing of RFRP neuronal activity (using hM4Diinduced silencing following $\mathrm{CNO}$ injection) would be sufficient to restore normal LH pulsatility in glucocorticoid-treated mice. For chronic glucocorticoid treatment, corticosterone implants were constructed based on a modification of a previously described design (Luo et al., 2016). Silicone rubber tubing ( $50 \mathrm{~mm}$ lengths, $2.16 \mathrm{~mm}$ outer diameter, filled with silicone rubber adhesive) was coated with a mixture of molten corticosterone (Santa Cruz Biotechnology) and cholesterol (Sigma Millipore; 85:15 ratio, respectively; $\sim 100 \mathrm{mg}$ of steroid per implant).

Male and female RFRP-hM4Di or control mice were all injected with CNO $(2 \mathrm{mg} / \mathrm{kg})$ and then sampled for LH pulsatility every $6 \mathrm{~min}$ for $3 \mathrm{~h}$, as described previously, beginning $30 \mathrm{~min}$ after the CNO injection. After the final sample, all mice were surgically implanted with a chronic subcutaneous corticosterone implant for at least $4 \mathrm{~d}$ (occasionally mice needed to be left 1-2 d longer so that the subsequent sampling could be conducted during diestrus). They were then injected with $\mathrm{CNO}$ and frequently blood sampled as before in the presence of the corticosterone implant. At the completion of the second frequent sampling period, they were perfused with $4 \%$ PFA for immunohistochemical brain section analysis of RFRP-3 and FRA. LH blood sampling was performed in the morning, and during diestrus in females. Blood samples were collected before and 3-5 d after corticosteroid implantation to measure serum corticosterone.

\section{Genotyping}

All mice were genotyped from tail tip DNA. The Rfrp-IRES-Cre line was genotyped using generic Cre primers (forward: 5' -CCT GGA AAA TGC TTC TGT CCG-3'; reverse: $5^{\prime}$-CAG GGT GTT ATA AGC AAT CCC$3^{\prime}$; annealing temperature $55^{\circ} \mathrm{C}$; product size indicating the Cre allele: $392 \mathrm{bp}$ ). Transgenic mice expressing tau-GFP were genotyped using the primers 5' -CGA AGT CGC TCT GAG TTG TTA TC-3', 5' -GCA GAT GGA GCG GGA GAA AT- $3^{\prime}$, and $5^{\prime}$-GCT CCT ATT GGC GTT ACT ATG-3'; annealing temperature $50^{\circ} \mathrm{C}$; product size indicating the floxed and WTs alleles: 400 and $600 \mathrm{bp}$, respectively. hM3Dq-DREADD mice were identified using the following PCR primer sets and annealing temperatures: flox primers, 5'-AAG GGA GCT GCA GTG GAG TA-3' (WT forward primer), 5' -CCG AAA ATC TGT GGG AAG TC-3' (WT reverse primer), $5^{\prime}$-ATG TCT GGA TCC CCA TCA AG-3' (mutant forward primer), and 5'-GAT GTT GCC GAT GAT GGT CAC-3' (mutant reverse primer); annealing temperature $55^{\circ} \mathrm{C}$; product size indicating the floxed and WTs alleles: 440 and $300 \mathrm{bp}$, respectively. Floxed diphtheria toxin receptor mice were identified using the following primers, $5^{\prime}$-AAA GTC GCT CTG AGT TGT TAT-3' (common forward primer), 5'-GGA GCG GGA GAA ATG GAT ATG-3' (WT reverse primer), and 5' -CAT CAA GGA AAC CCT GGA CTA CTG-3' (mutant reverse primer); annealing temperature $61^{\circ} \mathrm{C}$; product size indicating the floxed and WTs alleles: 603 and $242 \mathrm{bp}$, respectively. hM4Di-DREADD mice were identified using the following PCR primer sets and annealing temperatures: 
flox primers, 5'-ATG TCT GGA TCC CCA TCA AG -3' (forward primer), 5' -GAA GGC GCC TAT GAT GAG ATC-3' (reverse primer); annealing temperature $55^{\circ} \mathrm{C}$; product size indicating the floxed and WTs alleles: 440 and $300 \mathrm{bp}$, respectively.

\section{Immunohistochemistry}

All immunohistochemistry steps were performed at room temperature unless noted otherwise, and were separated by 4 washes in $0.05 \mathrm{~m}$ TBS. All sections were first blocked in $0.25 \%$ BSA made up in TBS containing $0.5 \%$ Triton- $\mathrm{X}$ for $20 \mathrm{~min}$. Once stained, the sections were mounted on slides and coverslipped using Vectashield mounting medium (Vector Laboratories) (fluorescent labels) or dehydrated and coverslipped using DPX mounting medium (immunoperoxidase with DAB label). All hypothalamic soma from at least four sections per animal were examined at $200 \times$ magnification using an Olympus BX45 microscope.

Tau - GFP or mCitrine + RFRP - 3, tau - GFP + TH, and tau GFP + oxytocin dual immunofluorescence. To dual-label for endogenous tau-GFP or mCitrine and RFRP-3, TH or oxytocin, the sections were incubated for $24-48 \mathrm{~h}$ at $4^{\circ} \mathrm{C}$ in polyclonal rabbit anti-sparrow GnIH (an RFRP-3 ortholog) (PAC 123a, kindly provided by Dr George Bentley, University of California Berkeley; 1:5000 dilution; RRID:AB_ 2531898) (Tsutsui et al., 2000; Kriegsfeld et al., 2006; Gibson et al., 2008; Henningsen et al., 2016), monoclonal mouse anti-TH (MAB318; Millipore; 1:10,000 dilution; RRID:AB_2201528) (Witkovsky et al., 2008), or monoclonal mouse anti-oxytocin (clone 4G11, Millipore MAB5296; 1:5000 dilution; RRID:AB_2157626) (Liu et al., 2002), and chicken anti-GFP (Aves Labs, GFP-1010; 1:5000 dilution; RRID:AB_ 2307313; also labels mCitrine) (Volkmann et al., 2010; Marques-Lopes et al., 2014) in TBS-Triton-X-BSA containing $2 \%$ normal goat serum. Sections were then incubated in AlexaFluor-568 goat anti-rabbit or antimouse IgG (1:500 dilution; Invitrogen, Thermo Fisher Scientific) and AlexaFluor-488 goat anti-chicken for $60 \mathrm{~min}$.

RFRP - $3+c F o s, R F R P-3+F R A$, and HA + cFos dual immunoperoxidase. cFos or FRA was colocalized with either RFRP-3 or HA using chromagenic dual-label immunohistochemistry. To label RFRP-3 or HA, sections were incubated in either 1:5000 rabbit anti-GnIH (PAC123a) or 1:500 rabbit anti-HA-Tag (C29F4) (Cell Signaling, \#3724; RRID:AB_1549585) (Kriz et al., 2017) in TBS-Triton-X-BSA containing $2 \%$ normal goat serum for 24-48 $\mathrm{h}$. This was followed by incubation in 1:1000 biotinylated goat anti-rabbit (Vector Laboratories) for $1 \mathrm{~h}$, in Vector Elite avidin-biotin complex solution (Vector Laboratories) for 1 $\mathrm{h}$ and in $0.5 \% \mathrm{DAB}$ and hydrogen peroxide solution (Sigma Millipore) for 5-7 min until a light brown stain was visible. Sections were then colabeled with either 1:5000 rabbit anti-cFos (Santa Cruz Biotechnology, sc52; RRID:AB_2106783) (Howorth et al., 2009) or 1:2000 rabbit anti-FRA (Santa Cruz Biotechnology, K-25; RRID:AB_2231996) (Spirovski et al., 2012) for 24-48 h. The cFos labeling was then directly revealed using HRP-conjugated goat anti-rabbit $\operatorname{IgG}(1: 500$, Dako) and nickel-enhanced DAB and hydrogen peroxide solution until a blueblack nuclear staining was observed.

TH single-label immunoperoxidase. The same protocol for RFRP-3 immunohistochemistry was used to stain for $\mathrm{TH}$; however, the primary antibody used was mouse anti-TH (MAB318; 1:10,000 dilution), and the secondary antibody used was biotinylated goat anti-mouse (Vector Laboratories, 1:1000).

\section{Hormone assays and pulse analysis}

LH. Whole-blood LH concentrations were assessed in unicate $50 \mu \mathrm{l}$ aliquots using a sensitive in-house sandwich ELISA, as previously described (Steyn et al., 2013). The assay sensitivity averaged $0.1 \mathrm{ng} / \mathrm{ml}$, and the interassay and intra-assay coefficients of variation were $<10 \%$. The diluted blood samples were snap frozen on dry ice; and at the end of the experiment, they were stored in $-20^{\circ} \mathrm{C}$ freezer. Basic criteria for identifying a pulse were as follows: (1) peaks of pulses must exceed both the preceding and following nadir concentrations (except where a clear peak was evident at the first sample, which were included to avoid pulse frequency underestimation); (2) a pulse must peak within two samples of the preceding nadir; and (3) the amplitude (peak concentration minus preceding nadir concentration) must be at least double the assay sensitivity, and the peak concentration must be at least 1.5 times the preceding nadir.

Corticosterone. Plasma corticosterone was measured using a commercially available kit (Arbor Assays, DetectX EIA \#K014-H5). The assay sensitivity was $20 \mathrm{pg} / \mathrm{ml}$, equating to a sample concentration of $2 \mathrm{ng} / \mathrm{ml}$ after correcting for sample dilution in the assay, and the interassay and intra-assay coefficients of variation were $<10 \%$.

\section{Statistics}

Results are presented as mean \pm SEM, and a value of $p<0.05$ was considered to be significant. Statistical analyses were performed by using unpaired Student's $t$ tests to compare single time point differences between two groups and one-way ANOVA to compare single time point differences among more than two groups. To compare group differences in response to treatment, repeated-measures two-way ANOVA was used whereby $\mathrm{CNO}$, corticosterone, and/or genotype were the factors for comparison. If a significant main effect or interaction was found, HolmSidak multiple-comparisons post hoc testing was used to identify where the difference(s) occurred. The effects of restraint stress on LH pulse frequency were analyzed using the Friedman test, followed by Dunn's multiple comparison test, since the limited time windows available for pulse analysis yielded nonparametric data. GraphPad Prism Software 8.0 was used for all analyses.

\section{Results}

\section{Validation of RFRP-Cre mice}

For these studies, we first validated and characterized a novel RFRP-Cre mouse by crossing the it with a tau-GFP reporter mouse. RFRP-Cre-GFP expression closely matched previously reported Rfrp gene and RFRP-3 peptide expression in mice (e.g., Poling et al., 2012; Gospodarska et al., 2019). RFRP-Cre-GFP soma were almost entirely confined to the DMH and the region between the $\mathrm{DMH}$ and the ventromedial hypothalamus. The rostral boundary of this population extended to the posterior region of the anterior hypothalamus, and the caudal boundary extended to the dorsotuberomammillary nucleus. Occasional cells were also seen in the arcuate nucleus. RFRP-Cre-GFP fibers were scattered throughout the brain; hypothalamic regions receiving prominent innervation included the anterior hypothalamic area, paraventricular, periventricular, dorsomedial hypothalamic, arcuate, and dorsotuberomammillary nuclei. Occasional fibers were visible in the internal zone of the median eminence (Fig. $1 D)$. We confirmed the specificity of Cre expression by performing dual-label immunohistochemistry to demonstrate that endogenous RFRP-3 peptide expression colabels with the RFRPCre GFP expression. As seen in Figure $1 E-H, \sim 80 \%$ of GFPexpressing cells coexpressed RFRP-3 labeling in both male and female mice, and a similar percentage of RFRP-3 cells expressed GFP. Consistent with previously described Rfrp tissue distribution (Hinuma et al., 2000), minimal RFRP-Cre-GFP expression was seen in testis, ovary, and kidney tissue (Fig. $1 I-K$ ), but in the retina, occasional strongly labeled cells were apparent in the photograph receptor and inner nuclear layers (Fig. $1 L$ ). In dual immunofluorescent staining with $\mathrm{TH}$ or oxytocin, the distribution of RFRP-Cre GFP neurons bordered and slightly overlapped with the A13/zona incerta dopamine and paraventricular nucleus (PVN) oxytocin neuronal populations, but no cells were colocalized ( 2 males and 2 females analyzed; data not shown).

\section{Validation of RFRP-hM3Dq knock-in mice}

Exogenous RFRP-3 has been shown to elicit stress and reproductive responses, but whether RFRP neurons are themselves capable of generating these responses is unknown. To determine this, we crossed the RFRP-Cre mice with hM3Dq-coupled DREADDs 


\section{A RFRP-3}

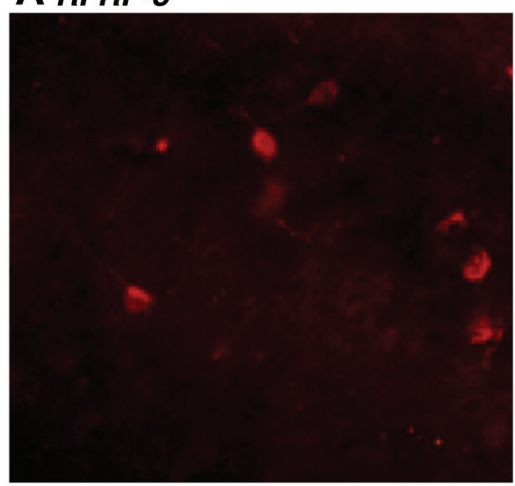

D DMH RFRP-3 + cFos

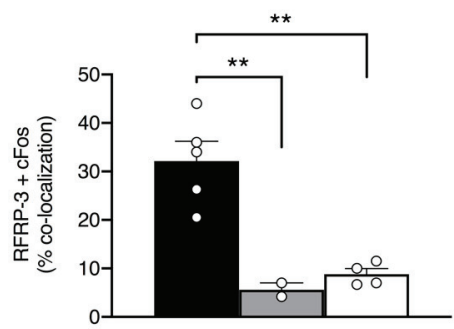

G DMH RFRP-3 + cFos

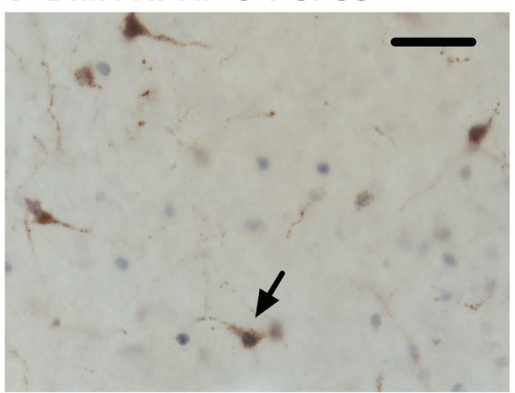

B RFRP-Cre-mCitrine

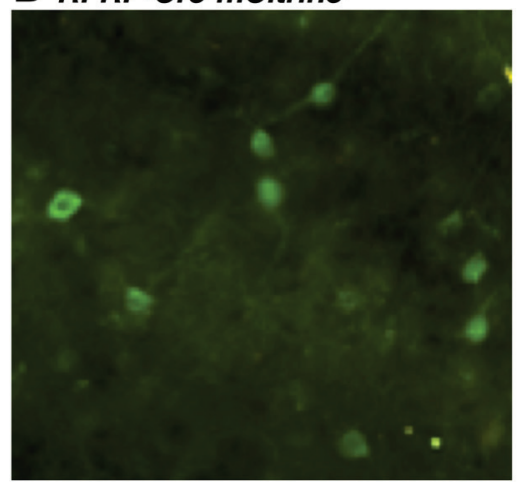

E DMH HA +cFos

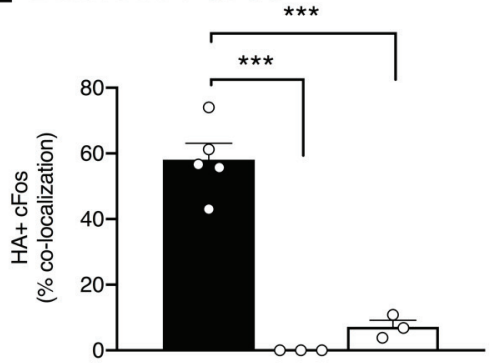

H DMH HA + cFos

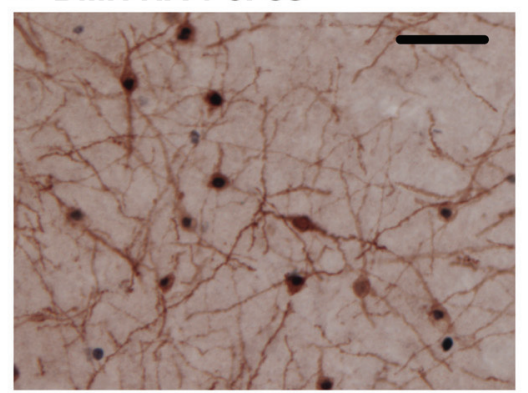

\section{Merge}

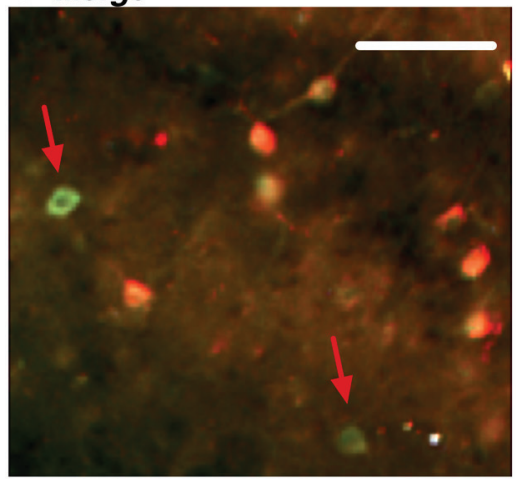

F PVN cFos

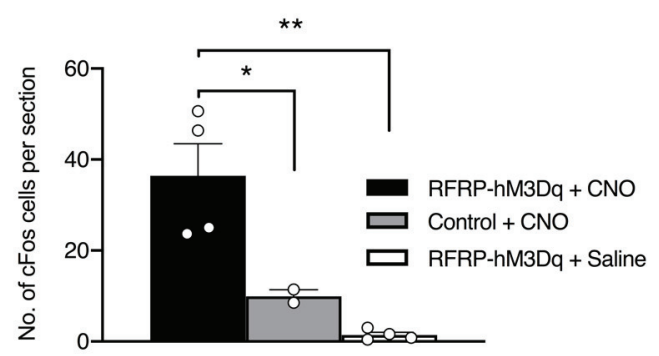

I PVNCFos

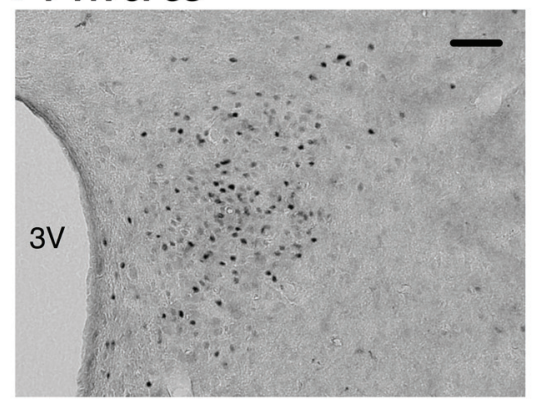

Figure 2. RFRP neurons colabel with RFRP-Cre-hM3Dq DREADD, revealed by mCitrine reporter expression, and CN0 treatment activates RFRP neurons in male and female RFRP-hM3Dq mice. Representative images from a female mouse showing RFRP-3 ( $\boldsymbol{A}$, red) and RFRP-Cre-mCitrine ( $\boldsymbol{B}$, green). $\boldsymbol{C}$, Yellow represents coexpression of RFRP-3 and RFRP-Cre mCitrine immunolabeling. RFRP-Cre mCitrine-labeled neurons not expressing RFRP-3 are identified by red arrows. $\boldsymbol{D}$, CN0-treated RFRP-hM3Dq mice (2 males, 3 females) exhibit significantly increased RFRP-3 + cFos coexpression compared with CN0-treated control mice (1 male, 1 female) $(p=0.0034)$ and saline-treated RFRP-hM3Dq mice $(2$ males, 2 females) ( $p=0.0019$, one-way ANOVA). Furthermore, (E) CN0-treated RFRP-hM3Dq mice exhibit significantly increased Cre-linked HA + cFos coexpression compared with CNO-treated control mice ( $p<0.0001)$ and saline-treated RFRP-hM3Dq mice ( $p<0.0001$, one-way ANOVA). $\boldsymbol{F}$, CNO treatment also significantly increased cFos expression in the PVN of RFRP-hM3Dq mice compared with CBO-treated control mice and saline-treated RFRP-hM3Dq mice ( $p=0.0029$, one-way ANOVA). G, Representative image showing RFRP-3 (brown labeling) + cFos (dark purple labeling) coexpression (example indicated by black arrow) in an RFRP-hM3Dq female in the dorsomedial nucleus in response to CNO treatment. $\boldsymbol{H}$, Representative image showing HA (brown labeling) + cFos (dark purple labeling) coexpression in an RFRP-hM3Dq female in the dorsomedial nucleus in response to CNO treatment. $I$, Representative image showing cFos immunolabeling in the PVN in an RFRP-hM3Dq female in response to CNO treatment. Data are mean \pm SEM. Scale bar, $50 \mu \mathrm{m}$. CNO was injected at a dose of $1 \mathrm{mg} / \mathrm{kg}$ subcutaneously, $1 \mathrm{~h}$ before perfusion and brain collection.

mice to investigate the effects of chronically activating RFRP neurons on glucocorticoid secretion, puberty onset, and estrous cyclicity. To validate these RFRP-hM3Dq mice, we first confirmed that the hM3Dq receptor was expressed in RFRP-3 neurons (Fig. $2 A-C)$. Similar to the RFRP-3 and tauGFP coexpression described above, $90.2 \pm 1.6 \%$ RFRP-3 neurons coexpressed the hM $3 \mathrm{Dq}$ tag mCitrine $(n=5)$. The distribution of mCitrine was confined to the $\mathrm{DMH}$ and the region between the $\mathrm{DMH}$ and the ventromedial hypothalamus as described above for tauGFP, but only $40.0 \pm 7.3 \%$ of all mCitrine-labeled cells coexpressed RFRP-3; this is consistent with the previously described loss of Rfrp expression in some cells during prepubertal development (Poling et al., 2012). We next confirmed that an injection of $\mathrm{CNO}$, which is the designer drug that activates the designer receptors, did indeed activate RFRP neurons by using immunohistochemistry to dual-label for either RFRP-3 or the DREADD-coupled HA epitope and cFos, which is an indirect marker for neuronal activity. As seen in Figure $2 D, G$, a significant 4- to 5-fold increase in RFRP + cFos coexpression was observed in CNO-treated RFRP-hM3Dq mice compared with saline-treated RFRP-hM3Dq mice $\left(t_{(8)}=5.273, p=0.0023\right)$ and CNO-treated control mice $\left(t_{(8)}=4.807, p=0.0027\right)$. Similarly, a significant 8 -fold increase in HA + cFos coexpression was observed in CNO-treated RFRP-hM3Dq mice compared with saline-treated RFRP-hM3Dq mice (Fig. $2 E, H ; t_{(8)}=8.631$, $p<0.0001)$. There was no coexpression of $\mathrm{HA}+\mathrm{cFos}$ in CNO-treated control mice as these mice did not exhibit any DREADD-coupled HA expression. In the same tissues, a pronounced cFos induction was evident in the PVN where $\mathrm{CRH}$ neurons are located in CNO-treated RFRP-hM3Dq mice 


\section{A Oral}

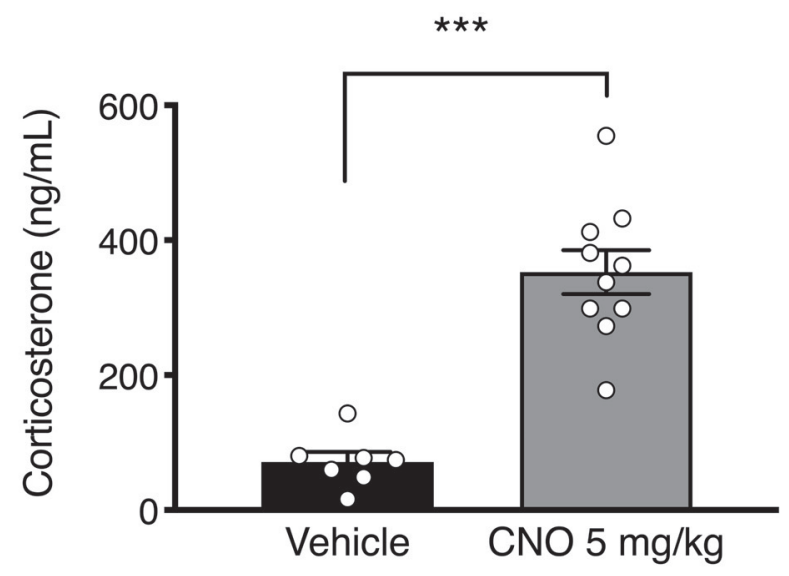

B Injection

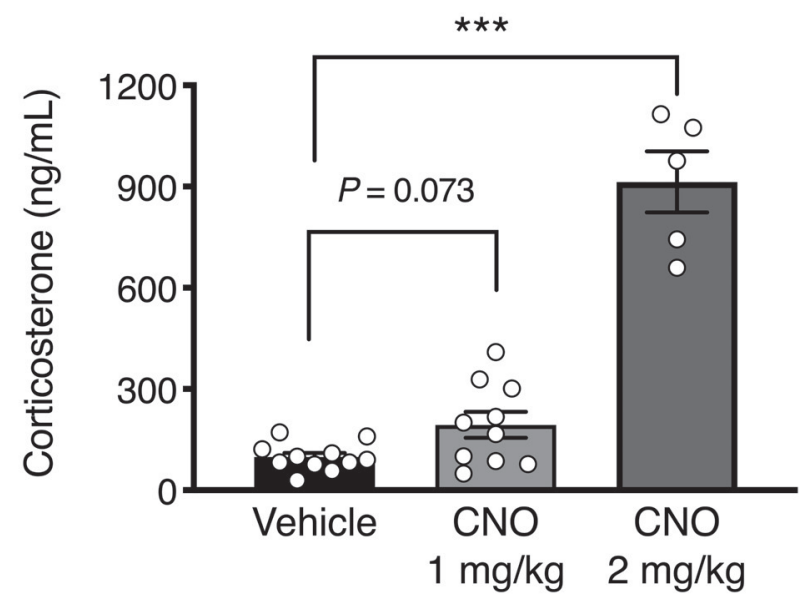

Figure 3. RFRP-hM3Dq neuronal activation stimulates corticosterone release. $A$, In response to an acute p.o. dose of CNO $(5 \mathrm{mg} / \mathrm{kg})$, male mice exhibited a significant increase in circulating corticosterone levels $(n=7-10$ mice per group; unpaired $t$ test, $p<0.0001)$. $\boldsymbol{B}$, In response to an acute subcutaneous injection of CNO (1-2 mg/kg), male mice exhibited a dose-responsive increase in circulating corticosterone levels ( $n=5-10$ mice per group; one-way ANOVA with Holm-Sidak's multiple comparisons test, $p=0.073, p<0.0001$ compared with vehicle-treated controls). Data are mean \pm SEM. The data for the two CNO doses in $\boldsymbol{B}$ were obtained in different runs, and the vehicle control data for these runs pooled. Blood samples were collected 90 min after CNO administration.

compared with saline-treated RFRP-hM3Dq mice $\left(t_{(7)}=\right.$ $5.338, p=0.0032)$ and CNO-treated control mice $\left(t_{(7)}=3.299\right.$, $p=0.0261)($ Fig. $2 F, I)$.

\section{Stimulation of glucocorticoid secretion by acute RFRP neuronal activation}

Acute activation of RFRP neurons in response to orally administered CNO $(5 \mathrm{mg} / \mathrm{kg})$ resulted in a significant $\sim 4$-fold increase in circulating corticosterone concertation after $90 \mathrm{~min}$ (Fig. $3 \mathrm{~A}$; $t_{(15)}=6.866, p<0.0001$ ), showing that RFRP neurons can drive glucocorticoid release. The same effect was evident in response to subcutaneous $\mathrm{CNO}$ injection, where a significant effect was observed in response to the $2 \mathrm{mg} / \mathrm{kg}$ CNO dose (Fig. $3 B ; t_{(23)}=$ $12.96, p<0.0001)$. Handling appeared to increase basal corticosterone levels in subcutaneously injected mice relative to orally dosed animals.

\section{Reproductive impairment by chronic RFRP neuronal activation}

We were next interested in determining the effect of chronic RFRP neuronal activation on different reproductive parameters. In males, chronic RFRP neuronal activation caused a delay in puberty onset, as measured by the age at which preputial separation occurred (Fig. 4A). In females, RFRP neuronal activation did not significantly affect puberty onset, as measured by the age of first estrus (Fig. $4 B ; t_{(40)}=0.712, p=0.481$ ). However, activating RFRP neurons significantly impaired estrous cyclicity. The CNO-treated RFRP-hM3Dq females exhibited significantly longer estrus cycles (Fig. $4 D ; t_{(22)}=2.211, p=0.038$ ), which was because of increased time spent in metestrus and diestrus (Fig. $4 C ; t_{(15.56)}=2.701$ ). With regards to fertility, both male and female mice were completely fertile. No differences were observed in the age at which male control versus RFRP-hM3Dq mice first successfully mated (resulting in a litter) (Fig. $4 E$; $t_{(21)}=$ $1.25, p=0.225$ ). Similarly, no differences were observed in female mice in either the time taken to birth their first litter after being paired with a fertile mate $\left(t_{(26)}=0.243, p=0.810\right)$ or in litter size $\left(t_{(26)}=0.876, p=0.389\right)$ (Fig. $\left.4 F\right)$.

\section{Validation of RFRP-ablated mice}

As seen in Figure $5 A$, we confirmed successful RFRP-3 neuronal ablation in diphtheria toxin-treated RFRP-Cre-positive mice expressing the Cre-dependent diphtheria toxin receptor (RFRPablated mice) by demonstrating a complete absence of RFRP-3 immunolabeling in RFRP-ablated males and females (8 of each sex), compared with $12.7 \pm 1.1$ neurons per section in controls ( 8 of each sex). To confirm the neuronal ablation was restricted to RFRP neurons, we examined the presence of neighboring $\mathrm{TH}$ neurons and showed no changes in $\mathrm{TH}$ protein expression (Fig. 5B).

\section{Modulation of acute restraint stress effects on glucocorticoid and LH secretion by ablation of RFRP neurons}

In male and female mice, ablation of RFRP neurons did not affect either the basal (females: $t_{(26)}=0.553$; males: $t_{(30)}=0.692$ ) or restraint-induced circulating concentration of corticosterone females: $t_{(26)}=1.984$; males: $\left.t_{(30)}=0.305\right)$ (Fig. $5 C, D$ ), indicating that these neurons are not required for robust glucocorticoid secretory responses.

Before investigating the role of RFRP neurons as mediators of stress-induced reproductive suppression, we first investigated whether RFRP ablation alone had any impact on estrous cyclicity in female mice. Under nonstressed conditions, no differences in the proportion of time spent in each cycle stage were observed between control versus RFRP-ablated mice $\left(t_{(16)}=0.949-1.804\right.$, $p>0.05)$. We also investigated whether RFRP neuronal ablation impacted the weight of seminal vesicles in males and uteri in females, as these organ weights can be used as proxy indicators of testosterone and estradiol levels, respectively. We found no differences in paired seminal vesicle weight between controls and RFRP-ablated mice $\left(9.8 \pm 0.4\right.$ vs $9.5 \pm 0.3 \mathrm{mg} / \mathrm{kg} \mathrm{BW;} t_{(22)}=$ $0.702, p>0.05)$ or uterine weight in control versus RFRP-ablated mice $\left(4.8 \pm 1.2\right.$ vs $\left.2.7 \pm 0.02 \mathrm{mg} / \mathrm{kg} \mathrm{BW} ; t_{(16)}=1.555, p>0.05\right)$.

We were next interested in determining whether RFRP neurons are critical mediators of stress-induced suppression of $\mathrm{LH}$ pulsatility. $\mathrm{LH}$ concentration and pulsatility were monitored in 


\section{A Preputial Separation}

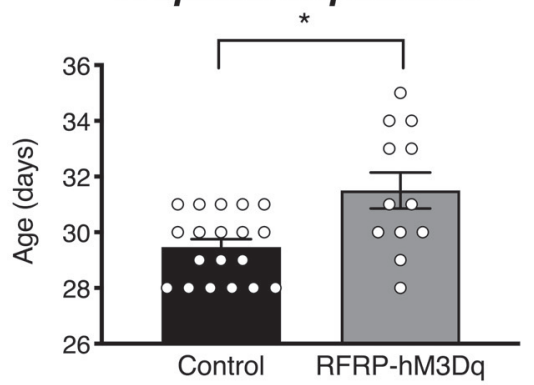

C Estrous Cyclicity

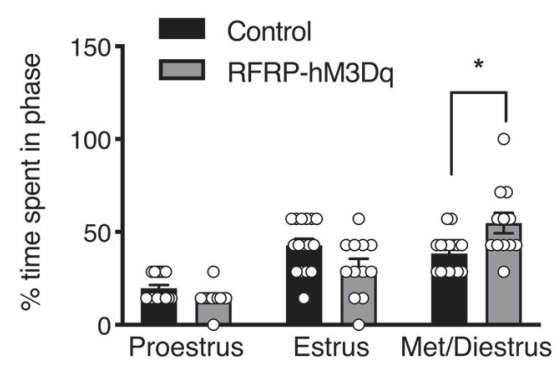

E Control cycle

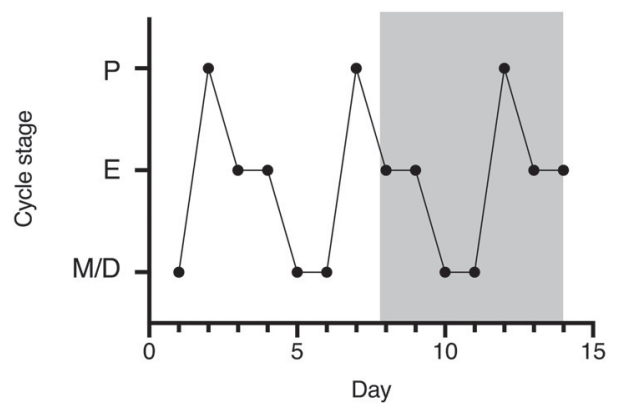

G Male Fertility

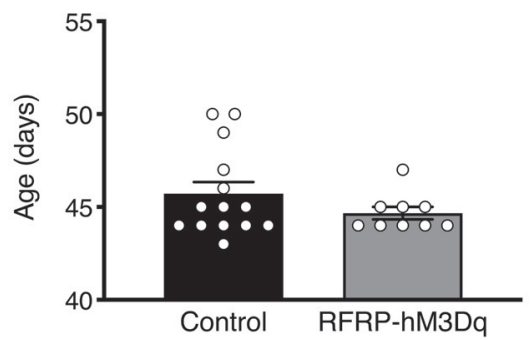

\section{B First Estrus}

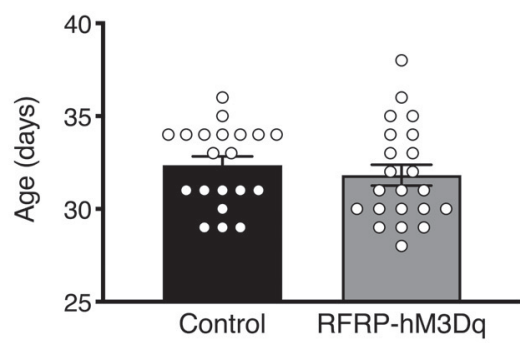

D Cycle Length

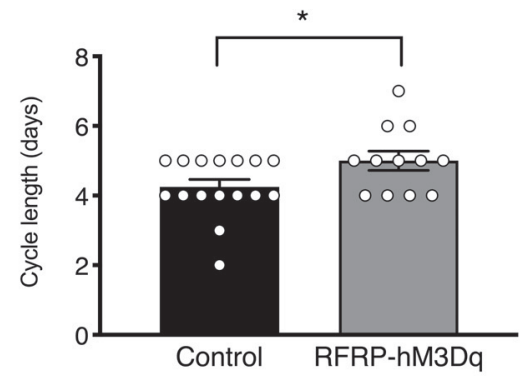

F RFRP-hM3Dq cycle

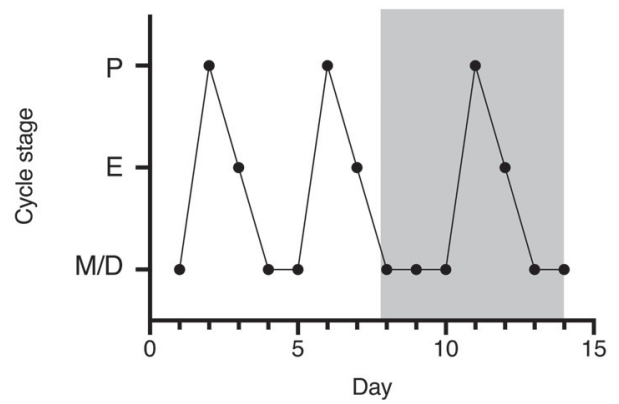

H Female Fertility

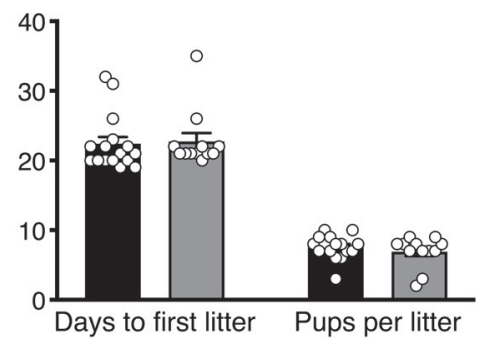

Figure 4. RFRP-hM3Dq neuronal activation delays male puberty onset and extends female cycle length. When chronically treated with CN0 in their drinking water (0.025 mg/ml p.0.) for $7 \mathrm{~d}$ from PND 26-35, $(\boldsymbol{A})$ male RFRP-hM3Dq mice $(n=12)$ exhibited a significant delay in the age of preputial separation compared with control mice ( $n=19)$ (unpaired $t$ test, $p=0.003$ ). $\boldsymbol{B}$, No differences in the age of first estrus were observed between female RFRP-hM3Dq $(n=22)$ and control $(n=20)$ mice (unpaired $t$ test, $p=0.481)$, however; (C) RFRP-hM3Dq mice ( $n=11)$ spent significantly longer in met/diestrus than control mice $(n=14)$ (two-way ANOVA with Holm-Sidak's multiple comparisons test, $p=0.047)$ and therefore $(\boldsymbol{D})$ had significantly longer cycle lengths (unpaired $t$ test, $p=0.038$ ) during another $7 \mathrm{~d}$ of postpubertal CNO treatment and cycle monitoring. Representative estrous cycles for a control $(\boldsymbol{E})$ and RFRP-hM3Dq $(\boldsymbol{F})$ female over the $14 \mathrm{~d}$ monitoring period, with the $7 \mathrm{~d}$ period of CNO treatment represented by gray shading. No differences were observed in fertility in ( $\boldsymbol{G})$ male or ( $\boldsymbol{H})$ female RFRP-hM3Dq mice compared with controls in response to another $7 \mathrm{~d}$ CNO treatment ( $n=10-16$ per group). Data are mean \pm SEM.

control and RFRP-ablated mice during a 90 min baseline period, $30 \mathrm{~min}$ restraint stress, and $45 \mathrm{~min}$ post-stress period. Females exhibited a significant interaction (group $\times$ time) in LH concentration $\left(F_{(2,24)}=5.6, p=0.010\right)$ and LH pulsatility $\left(F_{(2,24)}=3.6\right.$, $p=0.042)$. Post hoc testing revealed that control mice exhibited a trend toward a stress-induced suppression of LH concentration compared with the pre-stress period $\left(t_{(24)}=1.197, p=0.074\right)$, which became significant $\left(t_{(24)}=4.199, p=0.001\right)$ compared with the post-stress condition. Furthermore, they exhibited a stress-induced suppression of LH pulse frequency compared with the pre-stress $\left(z_{(24)}=2.405, p=0.048\right)$ and post-stress condition $\left(z_{(24)}=3.207, p=0.004\right)$ (Fig. $\left.6 A-C\right)$. In marked contrast, RFRP- 


\section{A RFRP-3 immunoreactivity}
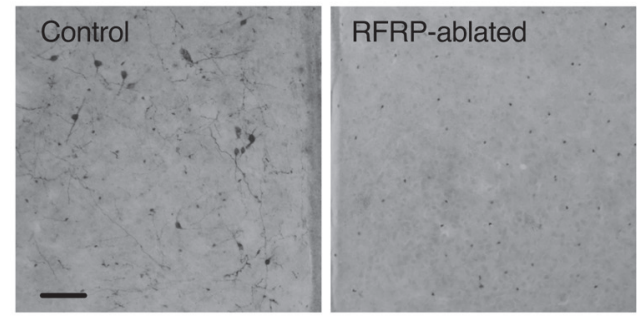

\section{Female corticosterone}

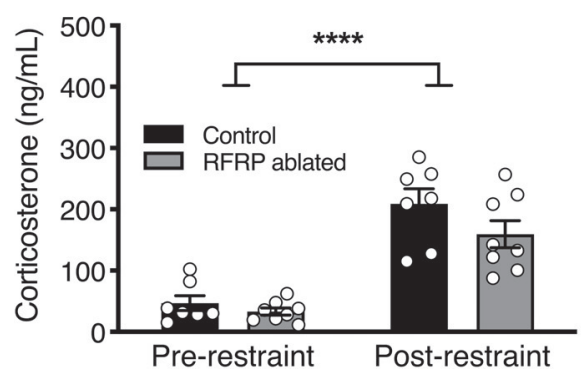

\section{B TH immunoreactivity}

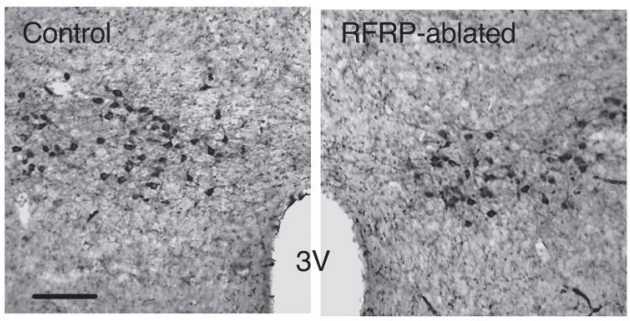

\section{Male corticosterone}

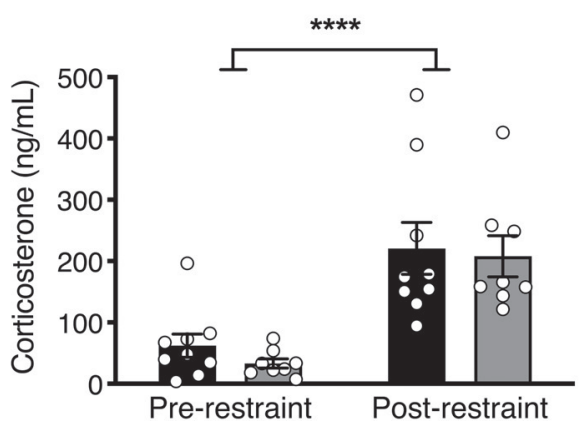

Figure 5. RFRP-ablated mice exhibit a complete loss of RFRP-3 immunolabeling. $\boldsymbol{A}$, Diphtheria toxin-treated female and male RFRP-ablated mice do not exhibit any RFRP-3-immunoreactive cells in the dorsomedial nucleus, $(\boldsymbol{B})$ yet maintain normal TH immunoreactivity in the adjacent zona incerta/A13 dopamine population ( $n=7-9$ per group). $\boldsymbol{C}, \boldsymbol{D}$, In response to an acute restraint stress, all mice exhibited a significant increase in circulating corticosterone concentration (two-way ANOVA, $p<0.001$ ) without any differences observed between male or female RFRP-ablated and control mice (Holm-Sidak's multiple comparisons test, $p>0.05 ; n=7-9$ per group). Data are mean \pm SEM. 3V, Third ventricle.

ablated females did not exhibit any stress-induced reduction in either LH concentration (vs pre-stress: $t_{(24)}=2.154, p=0.089$; vs poststress: $t_{(24)}=0.144, p=0.886$ ) or LH pulse frequency (vs prestress: $z_{(24)}=0.534, p>0.999$; vs post-stress: $z_{(24)}=0.134$, $p>0.999$ ) (Fig. $6 A, B, D$ ). During the restraint period, LH concentration was significantly lower in control females than in RFRP-ablated mice $\left(t_{(36)}=4.486, p=0.0002\right)$. Similarly, control male mice $\left(t_{(24)}=6.645, p<0.0001\right)$, but not RFRP-ablated mice $\left(t_{(24)}=1.750, p=0.253\right)$, exhibited the expected stress-induced suppression in LH concentration compared with the pre-stress condition (Fig. $6 E$ ). However, neither control $\left(z_{(24)}=1.336, p=0.544\right)$ nor RFRP-ablated $\left(z_{(24)}=0.802, p>0.999\right)$ male mice exhibited a significant reduction in $\mathrm{LH}$ pulse frequency in response to acute restraint stress compared with the pre-stress condition (Fig. 6F-H). When compared across groups over all time periods, mean LH concentration was significantly lower in the RFRP-ablated male mice (main treatment group effect: $\left.F_{(1,12)}=46.39, p<0.0001\right)$. No such differences were seen in females, or for pulse frequency in either sex.

\section{Validation of RFRP-hM4Di mice}

We used dual-label immunohistochemistry for RFRP-3 and FRA to confirm that an injection of CNO reduced the activity of RFRP neurons. As seen in Figure $7 A-D$, a significant decrease in RFRP + FRA coexpression was observed in CNO + corticosterone-treated RFRP-hM4Di mice compared with CNO + corticosterone-treated control mice (males: $t_{(17)}=5.838, p<0.0001$; females: $t_{(18)}=4.197$, $p=0.002)$. Furthermore, CNO + corticosterone-treated RFRPhM4Di male mice also showed a significant decrease in RFRP + FRA coexpression compared with control mice that were not treated with corticosterone $\left(t_{(17)}=2.309, p=0.034\right)$.

Modulation of glucocorticoid-induced suppression pulsatile LH secretion by RFRP neuronal silencing

Since chronic glucocorticoid treatment is able to disrupt LH pulses in female mice (Kreisman et al., 2020), we next sought to determine whether acute silencing of RFRP neurons could overcome chronic glucocorticoid-induced LH pulse suppression. As seen in Figure $7 E, F$, the corticosteroid implants produced a circulating corticosterone concentration of $610.4 \pm 18.5 \mathrm{ng} / \mathrm{ml}$ and $450.1 \pm 17.3 \mathrm{ng} / \mathrm{ml}$ in males and females, respectively, after $4 \mathrm{~d}$ of implant insertion (nonimplanted male and female mice had a circulating corticosterone concentration of $65.5 \pm 1.1 \mathrm{ng} / \mathrm{ml}$ and $80.4 \pm 14.4 \mathrm{ng} / \mathrm{ml}$, respectively). As expected, control females exhibited a significant corticosterone-induced suppression of $\mathrm{LH}$ concentration $\left(t_{(15)}=4.132, p=0.002\right)$ and $\mathrm{LH}$ pulse frequency $\left(t_{(15)}=8.475, p<0.0001\right)$ (Fig. $\left.8 A-D\right)$. In contrast to this, but in striking similarity to restraint-stressed RFRP-ablated females, RFRP-hM4Di females did not exhibit any reduction in either LH concentration $\left(t_{(15)}=0.125, p=0.902\right)$ or LH pulse frequency $\left(t_{(15)}=1.648, p=0.120\right)$ in response to corticosterone (Fig. $8 A, B$, $E, F)$. Unlike females, both control and RFRP-hM4Di male mice exhibited a significant corticosterone-induced suppression of LH concentration (controls: $t_{(13)}=2.176, p=0.049$; RFRP-hM4Di: $t_{(13)}=2.541, p=0.049$ ) and pulse frequency (controls: $t_{(13)}=$ 2.788, $p=0.030$; RFRP-hM4Di: $\left.t_{(13)}=2.438, p=0.030\right)($ Fig. $9 A-F)$.

\section{Discussion}

The ability of RFRP neurons to modulate stress and reproductive outcomes remains unclear, since animal models that enable experimental manipulation of their activity have not previously been developed. Here we describe new acute and chronic mouse models of RFRP neuronal activation, silencing and ablation, which we have used to clarify these roles. We first characterized and validated a novel RFRP-Cre mouse, in which endogenous RFRP-3 protein was closely coexpressed with Cre-driven GFP immunolabeling. The RFRP-Cre mouse allowed us to investigate, for the first time, the reproductive and stress response effects of stimulating, silencing, and ablating RFRP neurons. 


\section{A Female LH concentration}

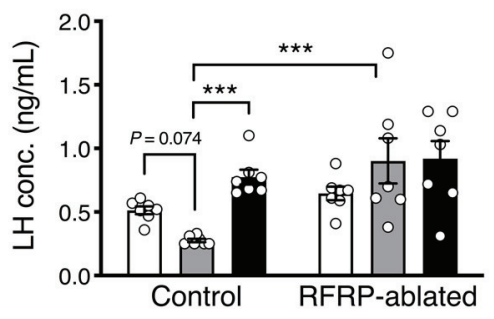

C Representative Control

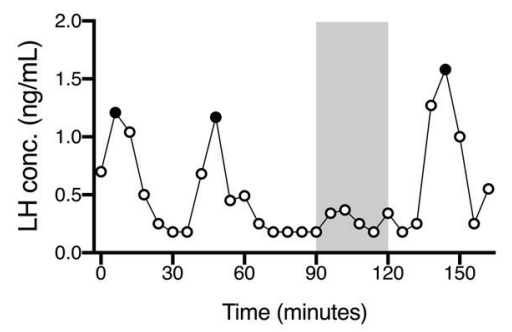

E Male LH concentration

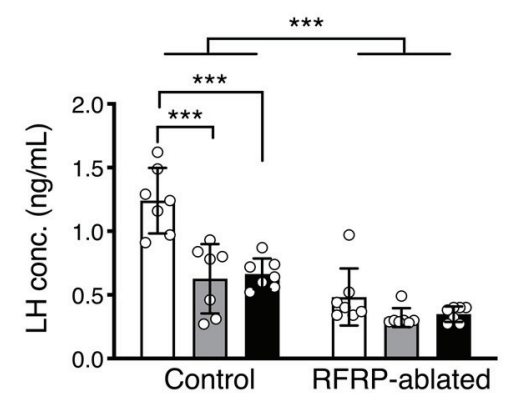

\section{G Representative Control}

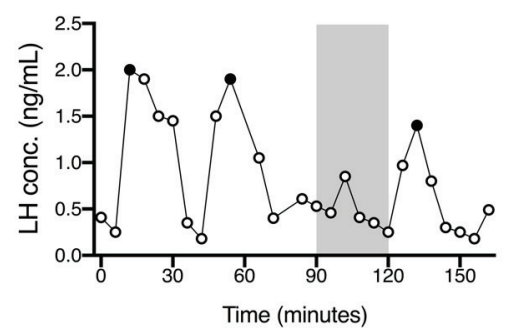

B Female LH pulse frequency

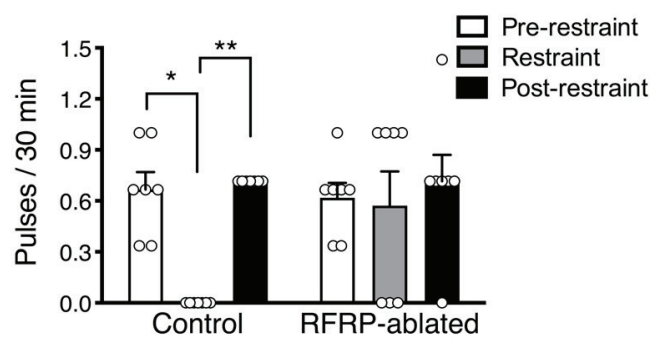

D Representative RFRP-ablated

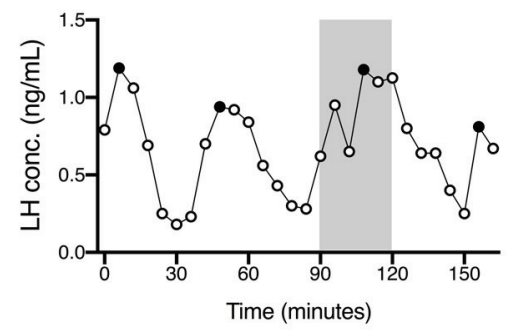

F Male $L H$ pulse frequency

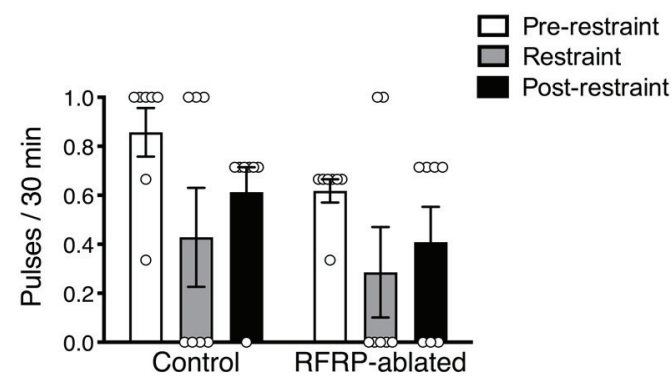

H Representative RFRP-ablated

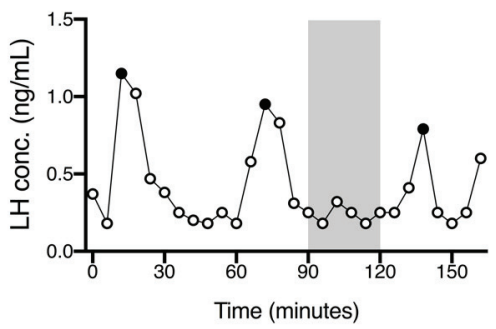

Figure 6. RFRP neuronal ablation prevents acute stress-induced LH suppression. $A, B$, In response to a 30 min restraint stress, female control mice, but not RFRP-ablated mice, exhibited a strong trend toward stress-induced suppression in average circulating LH concentration ( $p=0.074$ vs the 90 min pre-restraint period, and $p=0.001$ vs the 45 min post-restraint period) and a significant suppression in LH pulse frequency ( $p=0.048$ vs the pre-restraint period, and 0.004 vs the post-restraint period) ( $n=7$ per group). During restraint, LH concentration was significantly lower in control females than in RFRP-ablated mice $(p=0.0002)$. $C, D$, Representative examples of LH profiles in a control and RFRP-ablated female mouse. Gray shaded bars represent the 30 min restraint stress. $\boldsymbol{E}$, Control male mice exhibited a significant stress-induced suppression in basal LH $(p<0.0001)$ that was not observed in RFRP-ablated mice $(p=0.072)$, yet $(\boldsymbol{F})$ neither control nor RFRP-ablated male mice showed a stress-induced change in LH pulse frequency ( $n=7$ per group). $\boldsymbol{G}, \boldsymbol{H}$, Representative examples of $L H$ profiles in a control and RFRP-ablated male mouse. Two-way ANOVA and Holm-Sidak's multiple comparisons tests were used for analysis of LH concentration, while effects of restraint stress on LH pulse frequency were analyzed using the Friedman test followed by Dunn's multiple comparison test. Data are mean \pm SEM. Black circles represent pulse peaks.

The declining pattern of Rfrp mRNA expression during the postnatal/prepubertal developmental period raises the possibility that RFRP neurons may play a role in the mechanism that restrains activation of the reproductive axis before puberty (Poling et al., 2012). Therefore, we hypothesized that chronically activating RFRP neurons during the prepubertal/peripubertal window would cause a delay in puberty onset. In support of this hypothesis, we show that chronic activation of RFRP neurons causes a delay in male puberty onset. However, we saw no difference in the age of first estrus between control and RFRP-hM3Dq mice, although both Rfrp expression and Rfrp $+c$-Fos coexpression decrease significantly in female mice during the prepubertal 
A Male RFRP-3 + FRA

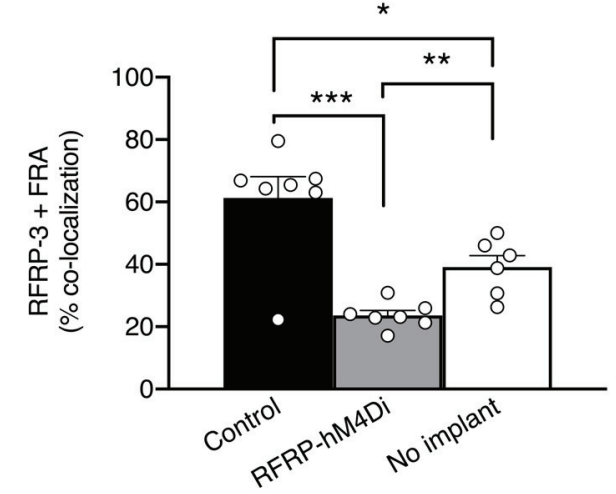

C Control

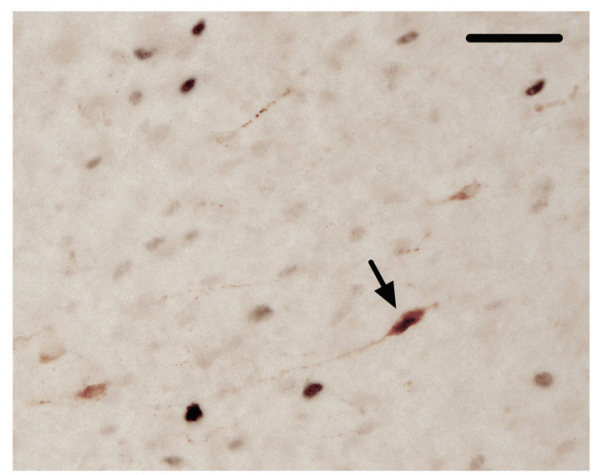

\section{E Male corticosterone}

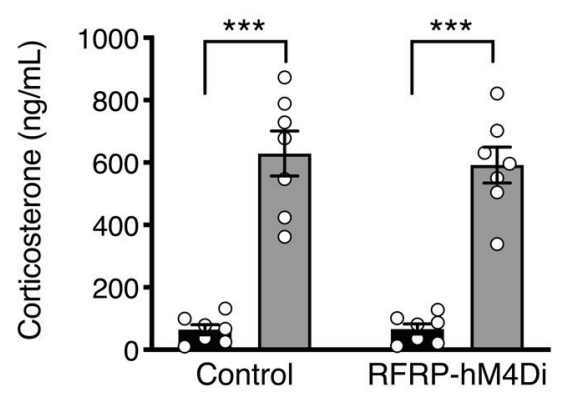

B Female RFRP-3 + FRA

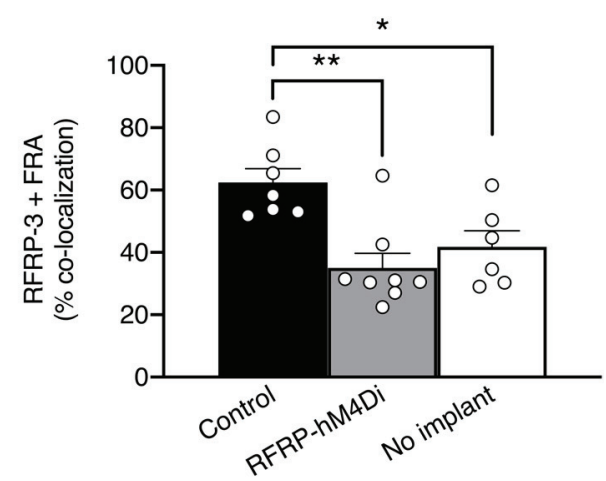

D RFRP-hM4Di

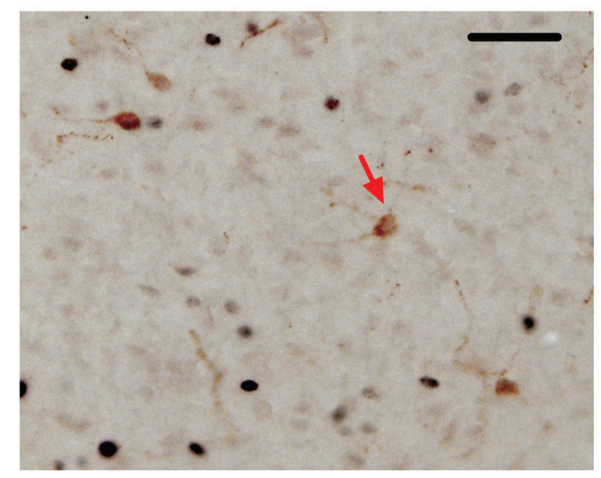

F Female corticosterone

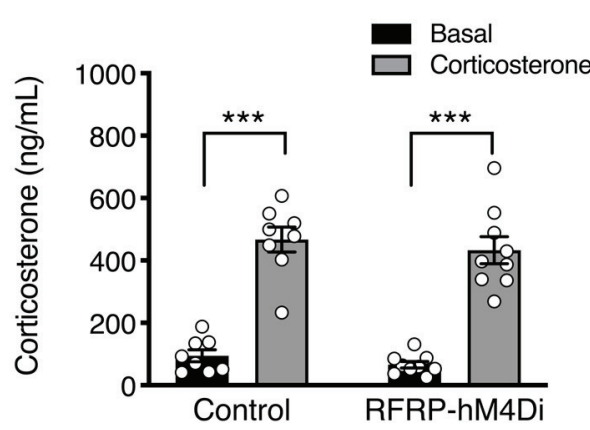

Figure 7. RFRP silencing reduces corticosterone-induced RFRP neuronal activity. A, In male mice treated with subcutaneous corticosterone implants for 4-6 $\mathrm{d}$, neuronal silencing (induced with $2 \mathrm{mg} / \mathrm{kg}$ CNO $90 \mathrm{~min}$ before perfusion) reduced RFRP+FRA coexpression in RFRP-hM4Di mice relative to controls $(p<0.0001)$. RFRP+FRA coexpression was also reduced relative to a separate cohort of mice with no corticosterone implants $(p=0.034)$ ( $n=6$ or 7 mice per group). $\boldsymbol{B}$, In female corticosterone-implanted mice, neuronal silencing with CNO reduced RFRP + FRA coexpression in RFRP-hM4Di mice relative to controls $(p<0.002)$. RFRP + FRA coexpression trended toward being reduced relative to a separate cohort of mice with no corticosterone implants $(p=0.073)$ ( $n=6-9$ mice per group). One-way ANOVA and Holm-Sidak's multiple comparisons tests were used to analyze coexpression data. $\boldsymbol{C}, \boldsymbol{D}$, Representative examples of RFRP-3+FRA immunohistochemical colocalization (black arrow) and RFRP neurons not colocalized with FRA (red arrow) in the dorsomedial nucleus. $\boldsymbol{E}, \boldsymbol{F}$, All male and female mice showed a significant increase in serum corticosterone concentration 3-5 d after receiving corticosterone implants compared with basal levels $(p<0.0001)$. Data are mean \pm SEM. Two-way ANOVA and HolmSidak's multiple comparisons tests were used for all corticosterone analyses. Scale bar, $50 \mu \mathrm{m}$.

stage (Poling et al., 2012). In general agreement with this malespecific puberty effect, mice that were null for the RFRP-3 receptor, GPR147, displayed a male-specific elevation of LH levels before and during puberty (León et al., 2014), suggesting that males might be more sensitive to this neuropeptide at this time. Chronic activation of RFRP neurons does appear to prolong estrous cyclicity, without significantly impacting fertility in either sex. RFRP neuronal activation decreases at the time of the preovulatory LH surge (Gibson et al., 2008; Semaan and Kauffman, 2015), suggesting that endogenous RFRP tone plays a role in controlling the time of the surge. At other times of the reproductive cycle, a high RFRP tone may have a minimal effect on the already low gonadotrophin output (Ancel et al., 2017), which is restrained by steroid negative feedback. Therefore, activating the RFRP neurons even further during the peripubertal period may not have a significant impact on the timing of female puberty, but may instead subtly influence the timing and magnitude of the LH surge. Furthermore, it is likely that the overwhelming reproductive drive supplied by the pubertal maturation of kisspeptin neurons overpowers the inhibitory effects of RFRP activation. Last, the magnitude of CNO-induced RFRP neuronal activation relative to physiological norms is 


\section{A Female LH concentration}

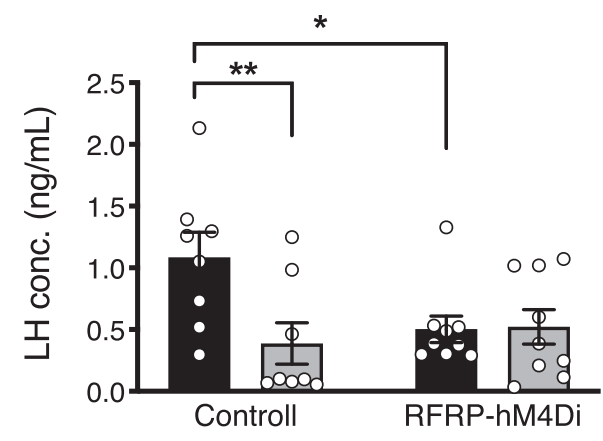

C Representative Control - basal

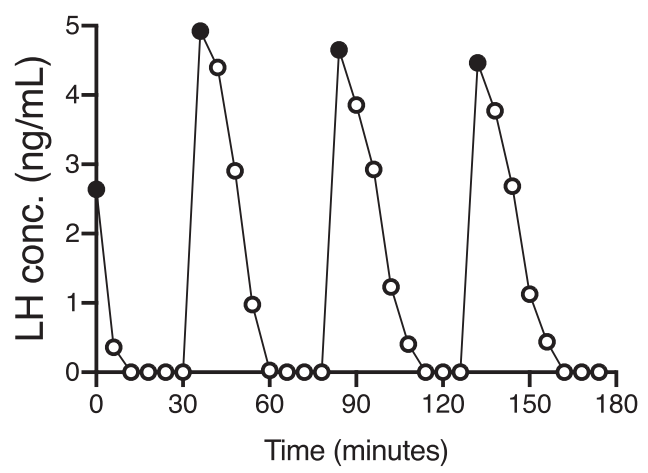

\section{E Representative RFRP-hM4Di - basal}

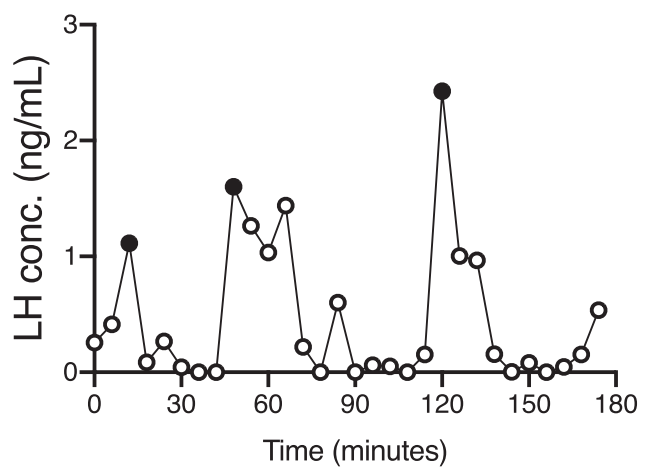

\section{B Female LH pulse frequency}

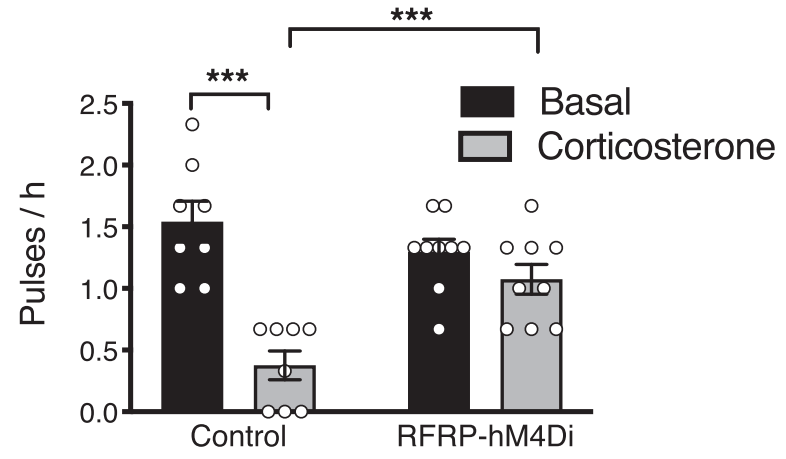

D Representative Control - cort

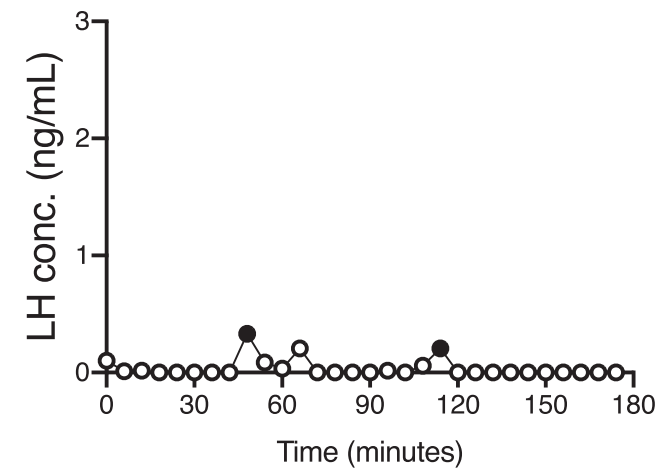

F Representative RFRP-hM4Di - cort

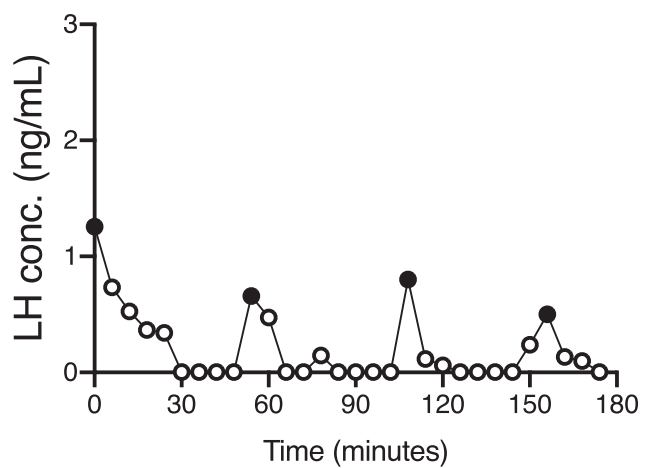

Figure 8. RFRP neuronal silencing prevents acute glucocorticoid-induced LH suppression in females. $A, B$, In response to at least $4 \mathrm{~d}$ of corticosterone treatment, female control mice, but not RFRP-hM4Di mice, exhibited a significant suppression in average circulating LH concentration $(p=0.0018$ ) and LH pulse frequency ( $p<0.0001$ ) ( $n=8$ or 9 per group). Tw0-way ANOVA and Holm-Sidak's multiple comparisons tests were used for all analyses of LH data. $\mathbf{C}-\boldsymbol{F}$, Representative examples of LH profiles in control and RFRP-hM4Di female mice under basal conditions and in response to corticosterone treatment. Data are mean \pm SEM. Black circles represent pulse peaks. CNO (2 mg/kg s.c.) was injected $30 \mathrm{~min}$ before the beginning of LH pulse sampling.

unknown; it may have been excessive for males but moderate (compared with normal cyclic fluctuations) in females. Nevertheless, these data show, for the first time, that RFRP neurons are able to balance reproductive drive, at least in some situations and in a sex-specific manner.

The HPA axis is governed by CRH neurons in the hypothalamic PVN. CRH stimulates the release of adrenocorticotropic hormone from the anterior pituitary gland, which in turn stimulates the production of adrenal glucocorticoids (Vale et al., 1981). The afferent inputs that modulate CRH neuronal activity are poorly characterized, but the dense expression of GPR147 in the PVN and projections of RFRP-3 fibers to this region highlight RFRP neurons as a possible modulatory input (Rizwan et al., 2012). We have previously shown that central RFRP-3 infusion activates the HPA axis and causes the release of corticosterone in mice (Kim et al., 2015), and the current data build on this 


\section{A Male LH concentration}

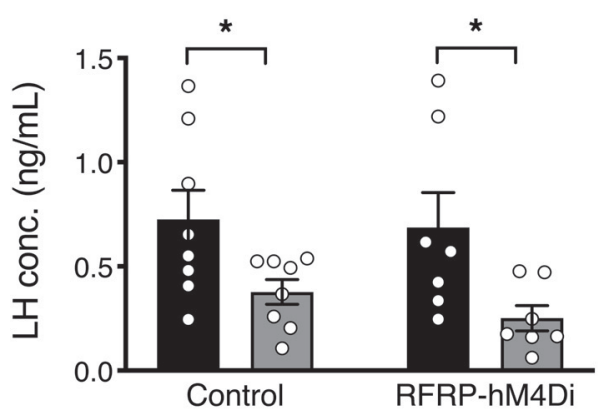

C Representative Control-basal

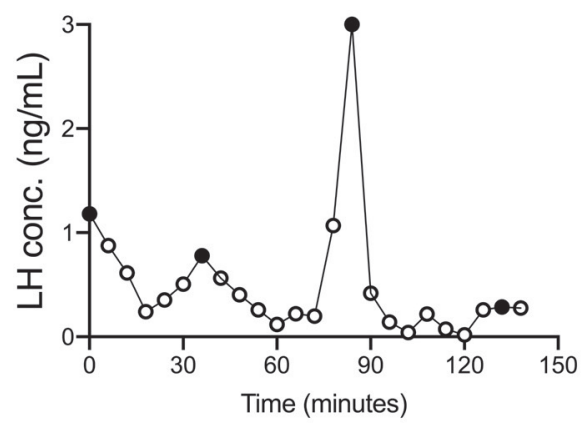

E Representative RFRP-hM4Di - basal

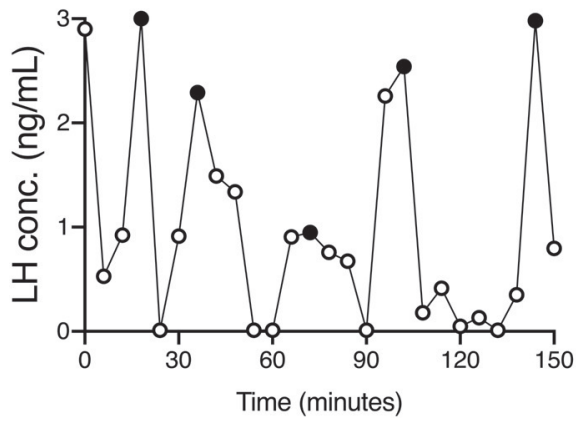

B Male $L H$ pulse frequency

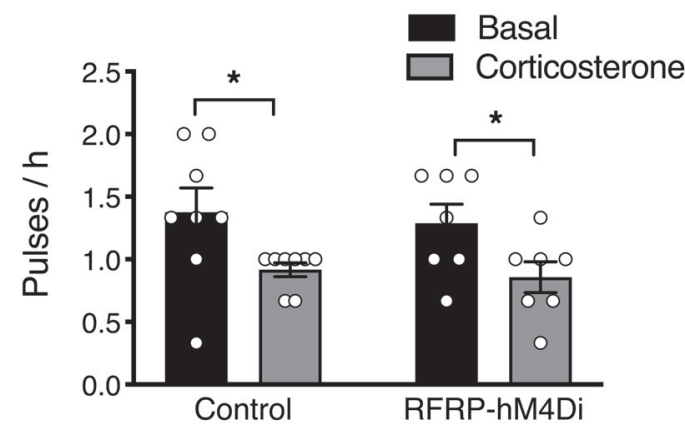

D Representative Control - cort

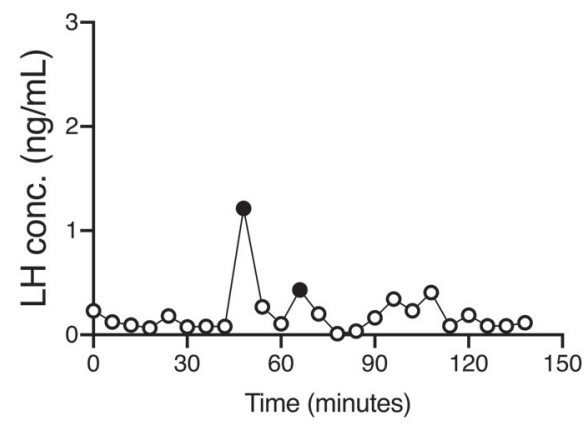

$\mathbf{F}$

Representative RFRP-hM4Di - cort

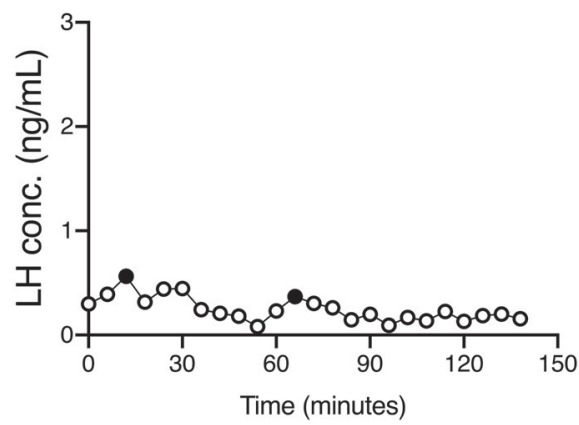

Figure 9. RFRP neuronal silencing does not prevent acute glucocorticoid-induced suppression of LH pulsatility in males. $A$, In response to $4 \mathrm{~d}$ of corticosterone treatment, male control mice and RFRP-hM4Di mice ( $n=7$ or 8 per group) both exhibited a significant suppression in average circulating LH concentration $(p=0.049)$. $\boldsymbol{B}$, Similarly, male control and RFRP-hM4Di mice both exhibited a significant suppression in LH pulse frequency $(p=0.030)$. Data are mean \pm SEM. Two-way ANOVA and Holm-Sidak's multiple comparisons tests were used for all analyses of $L H$ data. $\mathbf{C}-\boldsymbol{F}$, Representative examples of LH profiles in control and RFRP-hM4Di male mice under basal conditions and in response to corticosterone treatment. Black circles represent pulse peaks. CNO (2 mg/kg s.c.) was injected 30 min before the beginning of LH pulse sampling.

by demonstrating in RFRP-hM3Dq mice that acute activation of RFRP neurons causes a pronounced, dose-responsive release of corticosterone. This effect was pronounced under experimental conditions that were completely free of the confounding effects of handling stress. This proposed action of RFRP-3 on the HPA axis at the level of the PVN was further supported by the induction of cFos in this region in response to RFRP neuronal activation. Whether or not endogenous RFRP neuronal activation is also able to induce affective states associated with HPA axis hyperactivation, such as anxiety, as has been shown in response to central RFRP-3 infusions (Kim et al., 2015), remains to be tested. Nevertheless, our data suggest that RFRP-3 may be a part of a positive feedback loop whereby stress activates the release of RFRP-3, which in turn further activates the HPA axis.
Although chronic activation of RFRP neurons does not appear to act as a strong "brake" on fertility under normal conditions, RFRP neurons have been proposed to play a key modulatory role in certain situations, such as during times of stress (Kirby et al., 2009) when reproductive function is often thought to be impaired. Empirical evidence linking stress and human fertility is very limited, but perceived psychological distress and levels of the salivary stress biomarker $\alpha$-amylase have been negatively associated with female fecundity (Hjollund et al., 1999; Louis et al., 2011) and in vitro fertilization outcomes (Klonoff-Cohen et al., 2001). In female (Yang et al., 2017) and male (Yang et al., 2018) mice, psychosocial stress significantly reduced LH pulsatility and basal LH levels while concomitantly increasing Rfrp expression and Rfrp + cfos coexpression. 
Therefore, it may be that stress-induced RFRP activity acts in concert with other stress-induced neuropeptides and hormones, such as $\mathrm{CRH}$ and glucocorticoids, to dampen the HPG axis. To test whether RFRP neurons play a critical role in the mechanism whereby acute stress suppresses LH pulsatility, we generated RFRP-ablated mice and subjected them to an acute restraint stress. Remarkably, we demonstrate that female RFRPablated mice did not exhibit the stress-induced reduction in either LH concentration or pulse frequency that is observed in control mice. These data demonstrate that RFRP neurons play a critical role in mediating stress-induced LH suppression.

Interestingly, circulating LH concentration in males, but not females, was lower in RFRP-ablated mice compared with controls. While the significance of this is unclear, it is interesting to note that male-specific stimulation of $\mathrm{LH}$ secretion in response to infusion of RFRP-3 has been noted in hamsters (Ancel et al., 2012; Ubuka et al., 2012) and mice (Ancel et al., 2017), so lack of RFRP signaling could potentially reduce LH concentration. Nevertheless, seminal vesicle mass was not affected by RFRP neuronal ablation, implying that circulating androgen levels and therefore HPG axis function were within the normal range.

It remains unclear from this experiment whether RFRP neurons suppress reproductive function in direct response to the stressor or indirectly in response to HPA axis-induced glucocorticoid secretion. It should be noted that the period of restraint was limited to $30 \mathrm{~min}$, and stress-induced glucocorticoid release probably only began to occur toward the end of this brief time period (Yang et al., 2018). Therefore, RFRP neurons may activate in direct response to the stressor and interact with GnRH neurons to suppress pulse frequency independently of glucocorticoid levels, on a time scale of minutes. The rapid activation of RFRP neurons in response to restraint stress (Yang et al., 2018), presence of Gpr147 mRNA and contacts by RFRP neuronal processes on GnRH neurons (Rizwan et al., 2012), as well as responsiveness of GnRH neuronal firing frequency to RFRP-3 (Ducret et al., 2009) are consistent with this. On the other hand, RFRP neuronal activation (FRA colabeling) in response to corticosterone treatment (present results), glucocorticoid receptor presence on RFRP neurons and a requirement of the adrenal glands for chronic stress-induced Rfrp mRNA elevation (Kirby et al., 2009) all provide support for an indirect effect that occurs via HPA axis-induced glucocorticoid secretion. Both pathways seem likely to occur, with the direct RFRP response rapidly inhibiting $\mathrm{GnRH} / \mathrm{LH}$ pulses and glucocorticoid-mediated effects prolonging and amplifying the response.

In order to provide further support for the requirement of RFRP neuronal activity for stress-induced HPG axis suppression, while focusing specifically on glucocorticoid-induced suppression, we next investigated whether silencing RFRP neuronal activity during chronic glucocorticoid treatment restores HPG axis function. We first demonstrated that chronic glucocorticoid treatment caused a significant increase in cFos/FRA in RFRP neurons, and suppression of these levels in mice, which had a few hours of RFRP silencing before perfusion. These data reinforce previous studies showing that FRA expression can reliably be used as a marker of baseline neuronal activity (e.g., Lehman et al., 1996; Szawka et al., 2010). We next demonstrated that, as expected (Kreisman et al., 2020), in both male and female control mice, chronic glucocorticoid treatment caused a significant suppression of both LH concentration and LH pulsatility. Remarkably, female RFRP-hM4Di mice did not exhibit glucocorticoid-induced suppression of LH concentration or LH pulsatility. In contrast, male RFRP-hM4Di mice did show a significant suppression in LH concentration and pulsatility in response to glucocorticoid treatment. These data highlight the requirement of RFRP neurons in mediating glucocorticoid-induced HPG axis suppression (which is a common feature of the two stress paradigms we used), and suggest that this effect is most evident in females. It should also be noted that one other study has demonstrated a comparable requirement of $R f r p$ gene expression for stress-induced fertility suppression, also in female rodents (Geraghty et al., 2015). The fact that ablation or silencing of RFRP neurons overcame the effects of multiple models of stress in female mice greatly strengthens the case for a critical, sex-specific role of these neurons. The reason that this role of RFRP neurons is more evident in females is currently unknown, but it is noteworthy that estrogens are able to influence both RFRP and CRH neurons directly via estrogen receptor isoforms, whereas neither of these cell types expresses androgen receptors (Handa et al., 2009; Poling et al., 2012).

In conclusion, our data demonstrate that chronic RFRP neuronal activation can independently influence estrous cyclicity and male puberty onset, without significantly affecting fertility under normal conditions. However, we show that RFRP neurons do appear to be an essential component for stress-induced female reproductive hormone suppression. Our results build on previous findings that RFRP neurons are activated in response to stressful situations (Kirby et al., 2009; Yang et al., 2018) by demonstrating that RFRP neurons are indeed required for both acute restraint stress- and chronic glucocorticoid-induced HPG axis suppression. Whether they play a similar role for other types of stress-induced HPG axis suppression (e.g., immune stress, which is not glucocorticoid-dependent) (Debus et al., 2002) remains to be tested. Additionally, our data show that RFRP neuronal activation causes further HPA activation and glucocorticoid release, thereby demonstrating that a positive feedback loop exists whereby stressful stimuli activate RFRP neurons, which in turn cause further activation of the HPA axis.

\section{References}

Ancel C, Bentsen AH, Sebert ME, Tena-Sempere M, Mikkelsen JD, Simonneaux V (2012) Stimulatory effect of RFRP-3 on the gonadotrophic axis in the male Syrian hamster: the exception proves the rule. Endocrinology 153:1352-1363.

Ancel C, Inglis MA, Anderson GM (2017) Central RFRP-3 stimulates LH secretion in male mice and has cycle stage-dependent inhibitory effects in females. Endocrinology 158:2873-2883.

Beglopoulos V, Shen J (2004) Gene-targeting technologies for the study of neurological disorders. Neuromolecular Med 6:13-30.

Buch T, Heppner FL, Tertilt C, Heinen TJ, Kremer M, Wunderlich FT, Jung S, Waisman A (2005) A Cre-inducible diphtheria toxin receptor mediates cell lineage ablation after toxin administration. Nat Methods 2:419-426.

Debus N, Breen KM, Barrell GK, Billings HJ, Brown M, Young EA, Karsch FJ (2002) Does cortisol mediate endotoxin-induced inhibition of pulsatile luteinizing hormone and gonadotropin-releasing hormone secretion? Endocrinology 143:3748-3758.

Ducret E, Anderson GM, Herbison AE (2009) RFamide-related peptide-3, a mammalian gonadotropin-inhibitory hormone ortholog, regulates gonadotropin-releasing hormone neuron firing in the mouse. Endocrinology 150:2799-2804.

Dufourny L, Skinner DC (2002) Type II glucocorticoid receptors in the ovine hypothalamus: distribution, influence of estrogen and absence of colocalization with GnRH. Brain Res 946:79-86.

Ferin M (1999) Clinical review 105: stress and the reproductive cycle. J Clin Endocrinol Metab 84:1768-1774.

Geraghty AC, Kaufer D (2015) Glucocorticoid regulation of reproduction. Adv Exp Med Biol 872:253-278. 
Geraghty AC, Muroy SE, Zhao S, Bentley GE, Kriegsfeld LJ, Kaufer D (2015) Knockdown of hypothalamic RFRP3 prevents chronic stress-induced infertility and embryo resorption. Elife 4:e04316.

Gibson EM, Humber SA, Jain S, Williams WP 3rd, Zhao S, Bentley GE, Tsutsui K, Kriegsfeld LJ (2008) Alterations in RFamide-related peptide expression are coordinated with the preovulatory luteinizing hormone surge. Endocrinology 149:4958-4969.

Gospodarska E, Kozak LP, Jaroslawska J (2019) Isolation and identification of endogenous RFamide-related peptides 1 and 3 in the mouse hypothalamus. J Neuroendocrinol 31:e12668.

Handa RJ, Weiser MJ, Zuloaga DG (2009) A role for the androgen metabolite, $5 \alpha$-androstane- $3 \beta, 17 \beta$-diol, in modulating oestrogen receptor $\beta$-mediated regulation of hormonal stress reactivity. J Neuroendocrinol 21:351-358.

Henningsen JB, Poirel VJ, Mikkelsen JD, Tsutsui K, Simonneaux V, Gauer F (2016) Sex differences in the photoperiodic regulation of RF-amide related peptide (RFRP) and its receptor GPR147 in the Syrian hamster. J Comp Neurol 524:1825-1838.

Hinuma S, Shintani Y, Fukusumi S, Iijima N, Matsumoto Y, Hosoya M, Fujii R, Watanabe T, Kikuchi K, Terao Y, Yano T, Yamamoto T, Kawamata Y, Habata Y, Asada M, Kitada C, Kurokawa T, Onda H, Nishimura O, Tanaka M, et al. (2000) New neuropeptides containing carboxy-terminal RFamide and their receptor in mammals. Nat Cell Biol 2:703-708.

Hjollund NH, Jensen TK, Bonde JP, Henriksen TB, Andersson AM, Kolstad HA, Ernst E, Giwercman A, Skakkebæk NE, Olsen J (1999) Distress and reduced fertility: a follow-up study of first-pregnancy planners. Fertil Steril 72:47-53.

Howorth PW, Teschemacher AG, Pickering AE (2009) Retrograde adenoviral vector targeting of nociresponsive pontospinal noradrenergic neurons in the rat in vivo. J Comp Neurol 512:141-157.

Jasoni CL, Todman MG, Han SK, Herbison AE (2005) Expression of mRNAs encoding receptors that mediate stress signals in gonadotropinreleasing hormone neurons of the mouse. Neuroendocrinology 82:320328.

Kim JS, Brownjohn PW, Dyer BS, Beltramo M, Walker CS, Hay DL, Painter GF, Tyndall JD, Anderson GM (2015) Anxiogenic and stressor effects of the hypothalamic neuropeptide RFRP-3 are overcome by the NPFFR antagonist GJ14. Endocrinology 156:4152-4162.

Kirby ED, Geraghty AC, Ubuka T, Bentley GE, Kaufer D (2009) Stress increases putative gonadotropin inhibitory hormone and decreases luteinizing hormone in male rats. Proc Natl Acad Sci USA 106:11324-11329.

Klonoff-Cohen H, Chu E, Natarajan L, Sieber W (2001) A prospective study of stress among women undergoing in vitro fertilization or gamete intrafallopian transfer. Fertil Steril 76:675-687.

Kreisman M, McCosh R, Tian K, Song C, Breen K (2020) Estradiol enables chronic corticosterone to inhibit pulsatile LH secretion and suppress Kiss1 neuronal activation in female mice. Neuroendocrinology 110:501516.

Kriegsfeld LJ, Mei DF, Bentley GE, Ubuka T, Mason AO, Inoue K, Ukena K, Tsutsui K, Silver R (2006) Identification and characterization of a gonadotropin-inhibitory system in the brains of mammals. Proc Natl Acad Sci USA 103:2410-2415.

Kriz V, Krausova M, Buresova P, Dobes J, Hrckulak D, Babosova O, Svec J, Korinek V (2017) Establishment of a tagged variant of Lgr4 receptor suitable for functional and expression studies in the mouse. Transgenic Res 26:689-701.

Lehman MN, Durham DM, Jansen HT, Adrian B, Goodman RL (1996) Dopaminergic A14/A15 neurons are activated during estradiol negative feedback in anestrous, but not breeding season, ewes. Endocrinology 137:4443-4450.

León S, García-Galiano D, Ruiz-Pino F, Barroso A, Manfredi-Lozano M, Romero-Ruiz A, Roa J, Vázquez MJ, Gaytan F, Blomenrohr M, van Duin M, Pinilla L, Tena-Sempere M (2014) Physiological roles of gonadotropin-inhibitory hormone signaling in the control of mammalian reproductive axis: studies in the NPFF1 receptor null mouse. Endocrinology 155:2953-2965.

Liu HL, Cao R, Jin L, Chen LW (2002) Immunocytochemical localization of substance $\mathrm{P}$ receptor in hypothalamic oxytocin-containing neurons of C57 mice. Brain Res 948:175-179.
Louis GM, Lum KJ, Sundaram R, Chen Z, Kim S, Lynch CD, Schisterman EF, Pyper C (2011) Stress reduces conception probabilities across the fertile window: evidence in support of relaxation. Fertil Steril 95:2184-2189.

Luo E, Stephens SB, Chaing S, Munaganuru N, Kauffman AS, Breen KM (2016) Corticosterone blocks ovarian cyclicity and the LH surge via decreased kisspeptin neuron activation in female mice. Endocrinology 157:1187-1199.

Marques-Lopes J, Van Kempen T, Waters EM, Pickel VM, Iadecola C, Milner TA (2014) Slow-pressor angiotensin II hypertension and concomitant dendritic NMDA receptor trafficking in estrogen receptor beta-containing neurons of the mouse hypothalamic paraventricular nucleus are sex and age dependent. J Comp Neurol 522:3075-3090.

Mayer C, Acosta-Martinez M, Dubois SL, Wolfe A, Radovick S, Boehm U, Levine JE (2010) Timing and completion of puberty in female mice depend on estrogen receptor alpha-signaling in kisspeptin neurons. Proc Natl Acad Sci USA 107:22693-22698.

Poling MC, Kim J, Dhamija S, Kauffman AS (2012) Development, sex steroid regulation, and phenotypic characterization of RFamide-related peptide (Rfrp) gene expression and RFamide receptors in the mouse hypothalamus. Endocrinology 153:1827-1840.

Rizwan MZ, Porteous R, Herbison AE, Anderson GM (2009) Cells expressing RFamide-related peptide- $1 / 3$, the mammalian gonadotropin-inhibitory hormone orthologs, are not hypophysiotropic neuroendocrine neurons in the rat. Endocrinology 150:1413-1420.

Rizwan MZ, Poling MC, Corr M, Cornes PA, Augustine RA, Quennell JH, Kauffman AS, Anderson GM (2012) RFamide-related peptide-3 receptor gene expression in $\mathrm{GnRH}$ and kisspeptin neurons and GnRH-dependent mechanism of action. Endocrinology 153:3770-3779.

Semaan SJ, Kauffman AS (2015) Daily successive changes in reproductive gene expression and neuronal activation in the brains of pubertal female mice. Mol Cell Endocrinol 401:84-97.

Spirovski D, Li Q, Pilowsky PM (2012) Brainstem galanin-synthesizing neurons are differentially activated by chemoreceptor stimuli and represent a subpopulation of respiratory neurons. J Comp Neurol 520:154-173.

Steyn FJ, Wan Y, Clarkson J, Veldhuis JD, Herbison AE, Chen C (2013) Development of a methodology for and assessment of pulsatile luteinizing hormone secretion in juvenile and adult male mice. Endocrinology 154:4939-4945.

Szawka RE, Ribeiro AB, Leite CM, Helena CV, Franci CR, Anderson GM, Hoffman GE, Anselmo-Franci JA (2010) Kisspeptin regulates prolactin release through hypothalamic dopaminergic neurons. Endocrinology 151:3247-3257.

Tsutsui K, Saigoh E, Ukena K, Teranishi H, Fujisawa Y, Kikuchi M, Ishii S, Sharp PJ (2000) A novel avian hypothalamic peptide inhibiting gonadotropin release. Biochem Biophys Res Commun 275:661-667.

Ubuka T, Inoue K, Fukuda Y, Mizuno T, Ukena K, Kriegsfeld LJ, Tsutsui K (2012) Identification, expression, and physiological functions of Siberian hamster gonadotropin-inhibitory hormone. Endocrinology 153:373-385.

Vale W, Spiess J, Rivier C, Rivier J (1981) Characterization of a 41-residue ovine hypothalamic peptide that stimulates secretion of corticotropin and beta-endorphin. Science 213:1394-1397.

Volkmann K, Chen YY, Harris MP, Wullimann MF, Koster RW (2010) The zebrafish cerebellar upper rhombic lip generates tegmental hindbrain nuclei by long-distance migration in an evolutionary conserved manner. J Comp Neurol 518:2794-2817.

Witkovsky P, Gabriel R, Krizaj D (2008) Anatomical and neurochemical characterization of dopaminergic interplexiform processes in mouse and rat retinas. J Comp Neurol 510:158-174.

Wu M, Dumalska I, Morozova E, van den Pol AN, Alreja M (2009) Gonadotropin inhibitory hormone inhibits basal forebrain vGluT2-gonadotropin-releasing hormone neurons via a direct postsynaptic mechanism. J Physiol 587:1401-1411.

Yang JA, Song CI, Hughes JK, Kreisman MJ, Parra RA, Haisenleder DJ, Kauffman AS, Breen KM (2017) Acute psychosocial stress inhibits LH pulsatility and Kiss1 neuronal activation in female mice. Endocrinology 158:3716-3723.

Yang JA, Hughes JK, Parra RA, Volk KM, Kauffman AS (2018) Stress rapidly suppresses in vivo LH pulses and increases activation of RFRP-3 neurons in male mice. J Endocrinol 239:339-350. 